\title{
The G2-phase enriched IncRNA SNHG26 is necessary for proper cell cycle progression and proliferation
}

Helle Samdal ${ }^{2}$, Siv A. Hegre ${ }^{1}$, Konika Chawla ${ }^{1,4}$, Nina-Beate Liabakk ${ }^{1}$, Per A. Aas ${ }^{1}$, Bjørnar Sporsheim $^{1,5,6}$, and Pål Sætrom ${ }^{1,2,3,4, \neq}$

1. Department of Clinical and Molecular Medicine, Norwegian University of Science and Technology, 7491 Trondheim, Norway

2. Department of Computer Science, Norwegian University of Science and Technology, 7491 Trondheim, Norway

3. K.G. Jebsen Center for Genetic Epidemiology, Norwegian University of Science and Technology, 7491 Trondheim, Norway

4. Bioinformatics core facility - BioCore, Norwegian University of Science and Technology, 7491 Trondheim, Norway

5. Cellular \& Molecular Imaging Core Facility - CMIC, Norwegian University of Science and Technology, 7491 Trondheim, Norway

6. Central Administration, St Olavs Hospital, The University Hospital in Trondheim

‡) To whom correspondence should be addressed. Tel: +47 73594796; Email: pal.satrom@ntnu.no.

Running title (maks 40): SNHG26 affects cell cycle progression

Keywords (maks 5): SNHG26/IncRNA/cell cycle/MYC/oncogene 


\begin{abstract}
Long noncoding RNAs (IncRNAs) are involved in the regulation of cell cycle, although only a few have been functionally characterized. By combining RNA sequencing and ChIP sequencing of cell cycle synchronized HaCaT cells we have previously identified IncRNAs highly enriched for cell cycle functions. Based on a cyclic expression profile and an overall high correlation to histone 3 lysine 4 trimethylation (H3K4me3) and RNA polymerase II (Pol II) signals, the IncRNA SNHG26 was identified as a top candidate. In the present study we report that downregulation of SNHG26 affects mitochondrial stress, proliferation, cell cycle phase distribution, and gene expression in cis- and in trans, and that this effect is reversed by upregulation of SNHG26. We also find that the effect on cell cycle phase distribution is cell type specific and stable over time. Results indicate an oncogenic role of SNHG26, possibly by affecting cell cycle progression through the regulation of downstream MYCresponsive genes.
\end{abstract}

\title{
Introduction
}

LncRNAs are more than 200 nucleotides long with none or little protein coding potential. Most IncRNAs are transcribed by Pol II, polyadenylated, and spliced (Chen, 2016). LncRNAs can interact with DNA, RNA, and proteins, and are important regulators of gene expression at the epigenetic, transcriptional, and translational level. Among the different modes of mechanisms used by IncRNAs are the mediation of inter-chromosomal interactions, formation of nuclear bodies, and facilitating changes in histone modifications (Bohmdorfer and Wierzbicki, 2015). LncRNAs can further act as sponges to miRNAs, as scaffolds for chromatin modifying complexes, and as a guide or decoy of transcription factors (Marchese et al., 2017). To date, the Encyclopedia of DNA elements (ENCODE) project (GENCODE v35) has annotated 17957 IncRNA genes which give rise to 46977 different transcripts.

Compared to mRNAs, IncRNAs have a lower and more cell type-specific expression, with some being restricted to only a single cell type. There are also ubiquitously expressed IncRNAs that typically are involved in basal cellular functions that are essential for the cell's existence (Jiang et al., 2016). LncRNAs are involved in several cellular processes through a variety of mechanisms, and an aberrant expression of IncRNAs is associated with the pathogenesis of several diseases, including cancers where they are involved in tumorigenesis and progression. Specifically, several IncRNAs are important in the regulation of the cell cycle where they are involved in controlling the level of cell cycle regulators such as cyclins, cyclin-dependent kinases (CDKs), CDK inhibitors (CKIs), cell division cycle 25 (CDC25), E2 factor (E2F), and retinoblastoma (RB1) (Kitagawa et al., 2013).

One specific class of IncRNAs are small nucleolar RNA (snoRNA) host genes (SNHG). SnoRNAs consist of 60-300 nucleotides, accumulate in the nucleoli, and are involved with ribosomal RNA (rRNA) processing and the regulation of gene expression (Liang et al., 2019). SnoRNAs are generated from introns only, but if the full-length spliced transcript including exons exist as a stable molecule, it is classified as an SNHG. SNHGs have oncogenic properties connected to proliferation, invasion, metastasis, and cell cycle progression, are often overexpressed in cancers, and may represent biomarkers for disease progression and novel therapeutic targets (Zimta et al., 2020, Williams and Farzaneh, 2012). For nuclear localized SNHGs, the main molecular mechanisms previously reported are modulation of methylation enzymes affecting the DNAs methylation state, and repression of gene transcription through the interaction with transcription factors. Meanwhile, SNHGs located in the cytoplasm have functions like miRNA sponging, repression of translation through direct binding of mRNAs, and interference with protein ubiquitination (Zimta et al., 2020). 
SNHG26 is a multi-exonic gene that hosts the snoRNA SNORD93, which can be further processed into a small nucleolar RNA-derived RNA (sdRNA-93) with miRNA-like functions associated with malignancy of breast cancer (Patterson et al., 2017). Previous studies have identified SNHG26 as dysregulated in cancers including multiple myeloma, bladder, and lung cancer (Liu et al., 2019, Bao et al., 2017, Hu et al., 2017).

In a previous study we combined RNA sequencing (RNA-seq) with ChIP sequencing (ChIPseq) of cell cycle synchronized HaCaT cells and identified 59 IncRNAs with cell cycle-dependent expression and correlated changes in Pol II occupancy or promoter activity as measured by H3K4me3 and histone 3 lysine 27 trimethylation (H3K27me3) signals (preprint: https://doi.org/10.1101/2021.02.12.430890). Of these cell cycle-associated IncRNAs, SNHG26 (also known as $A C 005682.5$ ) had the highest overall correlation, and its biological function was investigated by siRNA-mediated knockdown followed by cell cycle- and proliferation assays. Downregulation of SNHG26 resulted in reduced proliferation in HaCaT, A549, LS411N, and DLD1 cells. We also observed a reduction of $\mathrm{HaCaT}$ cells present in the $\mathrm{G} 1$ phase and an enrichment of cells present in the G2/M phase of the cell cycle in response to SNHG26 knockdown, indicating a possible role in the $\mathrm{G} 2$ to $\mathrm{M}$ progression (preprint: https://doi.org/10.1101/2021.02.12.430890).

In the present study, we further characterized the biological function and provide some mechanistic insight into the oncogenic properties of SNHG26. We used siRNA, ASO, or CRISPR interference and CRISPR activation (CRISPRi and CRISPRa, respectively) to modulate the expression of SNHG26 to evaluate its cis- and trans regulatory abilities and to investigate how it affects proliferation, mitochondrial stress, and cell cycle phase distribution. We used RNA FISH to determine the subcellular localization of SNHG26 to be mainly nuclear in HaCaT, A549, and LS411N cells, with high-intensity spots surrounded by nuclear and extranuclear low-intensity spots. We report that SNHG26 affects cell cycle phase distribution in all three investigated cell lines, and that the phase distribution is stable and cell-type specific. Moreover, downregulation of SNHG26 reduced the viability and caused increased mitochondrial stress. We also find that SNHG26 has cis-regulatory abilities as it regulates the expression of its neighbor mRNA TOMM7, and that this effect is posttranscriptional. Furthermore, CRISPR-mediated upregulation of SNHG26 reversed the effect on phase distribution, proliferation, mitochondrial stress, and TOMM7 expression. Finally, through RNAseq analysis we identified several significantly opposite expressed genes in CRISPRa compared to CRISPRi as MYC-responsive genes enriched for $\mathrm{GO}$ terms that included cell cycle G1/S transition, G2/M checkpoints, and DNA replication. SNHG26 is itself a direct MYC target gene, and our results suggest that it affects cell cycle and proliferation through feed forward regulation of other MYCresponsive genes.

\section{Results and discussion}

\section{SNHG26 is mainly localized in the nucleus}

SNHG26 is localized at chromosome 7 (ENSG00000228649, chr7:22,854,126-22,872,945) between protein coding genes TOMM7 and FAM126A (Figure 1A). Based on tissue expression data from the Genotype-Tissue Expression (GTEx) project, SNHG26 is expressed across most tissue types, except for the brain, where it is barely detected (Figure 1A; Supplementary Figure S1). The primary sequence of SNHG26 has limited conservation outside primates, but the TOMM7-FAM126A locus is conserved in jawed vertebrates and the snoRNA SNORD93, located in SNHG26's second intron, is conserved in amniota (Supplementary Figure S2) (Gardner et al., 2015). Moreover, the genomic 
blocks containing SNHG26's exons are largely conserved among placental mammals, and the genomic region surrounding SNORD93 in both placentals and other amniota is transcribed (Supplementary Figure S3). Thus, SNHG26 appears to have both conserved exon-intron structure, synteny, and expression in placentals.

Data from the IncATLAS database (https://Incatlas.crg.eu/), which present nuclear localization as the log ratio of relative nuclear to cytoplasmic RNA levels as measured by RNA-seq (relative concentration index, $\mathrm{RCI}$ ), indicate that $S N H G 26$ is enriched in the nucleus across a broad set of cell lines (average $\mathrm{RCl}=-2.03$, Figure $1 \mathrm{~B}$ ). In comparison, the nuclear and cytoplasmic IncRNAs MALAT1 and DANCR have average RCls of -5.12 and 0.68 , respectively (Figure $1 \mathrm{~B}$ ). We confirmed the subcellular localization of SNHG26 using RNA FISH in HaCaT, A549, and LS411N cells. There, SNHG26 is mainly localized in the nucleus where it appears as two to five bright nuclear foci as well as nuclear and extranuclear low-intensity spots (Figure 1C). The appearance of SNHG26 as low and high intensity spots may represent trans and cis functional mechanisms, respectively.

The bright nuclear foci are consistent with functions connected to chromatin regulation and imprinting, such as for XIST and AIR $[8,16]$. These IncRNAs accumulate at their site of action, and their presence suggests active silencing of the specific genomic location (Wang and Chang, 2011). Bright foci may also be consistent with the appearance of IncRNAs that are localized in subnuclear compartments or structures, such as Cajal bodies, the nucleolus, paraspeckles, nuclear speckles, perinucleolar, and perichromatin regions (Singh and Prasanth, 2013, Fay and Anderson, 2018). As $\mathrm{HaCaT}, \mathrm{LS} 411 \mathrm{~N}$, and A549 are all characterized as aneuploid cell lines with chromosome numbers that may be compatible with the number of high-intensity spots observed in these cell lines (Knutsen et al., 2010, Briffa et al., 2015, Peng et al., 2010, Boukamp et al., 1988), the high-intensity spots of SNHG26 in the nucleus are possibly caused by an accumulation of its transcripts at their site of transcription.

According to Cabili et.al., the appearance of bright nuclear foci could imply that the IncRNA is involved in maintaining the epigenetic state during cell division, and to address this they investigated whether the nuclear foci persisted and remained attached to the chromosomes through mitosis (Cabili et al., 2015). To examine whether the nuclear high-intensity spots of SNHG26 would persist during mitosis, we compared the intensity and number of spots in mitotic and non-mitotic $\mathrm{HaCaT}$ cells. The average number of spots associated with the DNA was similar in mitotic (6.8) and non-mitotic (7.3) cells (Figure 1D and 1E), yet few high-intensity spots ( $>5000$ intensity) were detected in cells undergoing mitosis compared to non-mitotic cells (Figure 1D and 1F; Supplementary Figure S4). Spots associated with the DNA in mitotic and non-mitotic cells had an average intensity of 1495 and 8015 , respectively. Based on these results, high-intensity spots are largely lost in mitotic cells, yet the number of spots that co-localize with DNA is similar. Thus, we cannot exclude that SNHG26 may have functions connected to epigenetic maintenance through cell division, which warrants further investigations.

We only included the spots that co-localized with the stained DNA for the image analysis (Figure 1E-F), which excluded spots that were localized outside the DNA in mitotic cells, yet possibly within the nuclear membrane (Supplementary Figure S5). Consequently, the total number of spots present within the nucleus are probably higher in mitotic cells than the analysis suggests. This was supported by a visual inspection, where it appears to be several low-intensity spots surrounding the DNA in mitotic cells, probably within the nuclear membrane (Supplementary Figure S5). 


\section{SNHG26 affects proliferation and cell cycle phase distribution}

Our previous data showed that knockdown of SNHG26 resulted in growth inhibition in four different cell lines (preprint: https://doi.org/10.1101/2021.02.12.430890) 48 hours after transfection. To investigate whether this effect was consistent over time, we used ASO to knockdown SNHG26 in $\mathrm{HaCaT}, \mathrm{A} 549$, and LS411N cells (Supplementary Figure S6), followed by cell counting. A significant growth reduction of cells was observed in all three cell lines, with an average reduction of $32 \%$ and $57 \%, 48$ and 72 hours after transfection, respectively (Figure $2 \mathrm{~A}$ ).

To further investigate the functions and biological effects of SNHG26 expression, we generated $\mathrm{HaCaT}$ and $\mathrm{A} 549$ cells stably expressing catalytically inactive CAS9, dead CAS9 (dCAS9), fused with either the Krüppel-associated box (KRAB) repressing domain or multiple activating domains, providing tools for, respectively, transcriptional inhibition (CRISPRi) or activation (CRISPRa) (Figure 2B; Supplementary Figure S7). Consistent with the reduced cell counts following ASO and siRNA-mediated knockdown of SNHG26, transcriptional inhibition of $S N H G 26$ reduced the metabolic activity of $\mathrm{HaCaT}$ cells, while its activation increased the metabolic activity (Figure $2 \mathrm{C}$ ). The reduction of metabolic activity was validated by siRNA-mediated knockdown of SNHG26 in HaCaT cells, with $12 \%$ reduction 48 hours after transfection (Supplementary Figure $\mathrm{S} 8$ ).

Further we used CRISPRi/a to investigate whether modulation of SNHG26 transcription affected the cell cycle distribution in HaCaT and A549 cells. We used a hierarchical, linear model to calculate the combined effect on cell cycle phase distribution between CRISPRi and CRISPRa, requiring opposite contributions of the two assays and assuming a random effect for each assay. In $\mathrm{HaCaT}$ cells we observed a significant difference in cell cycle distribution for the G1 and G2/M phases, whereas for A549 we observed a significant difference for all cell cycle phases (G1, S, and G2/M) between CRISPRi and CRISPRa (Figure 2D). For both cell lines, CRISPRi resulted in a reduction of cells in the $\mathrm{G} 1$ phase and an enrichment of cells in the G2/M phase, though for A549 cells, the enrichment in the $S$ phase was higher (Figure 2D). As expected, the opposite trend was observed when upregulating SNHG26 by CRISPRa, which resulted in an enrichment and reduction in the G1 and $S$ phases, respectively, of both cell lines (Figure 2D). To investigate whether the cell cycle phase distribution was stable over time, CRISPRi/a-modified HaCaT cells were harvested and re-seeded followed by cell cycle assays eight days after gRNA transduction with SNHG26-specific gRNA or nontarget control gRNA. Indeed, the cell cycle phase distribution was the same as before re-seeding with significant difference in cell cycle distribution for the $\mathrm{G} 1$ and G2/M phases between CRISPRi and CRISPRa, suggesting that the effect is not transient, but stable over time (Supplementary Figure S9).

To investigate whether the effect on cell cycle phase distribution was consistent when using other gene modulation techniques, we performed ASO- and siRNA-mediated knockdown of SNHG26 in $\mathrm{HaCaT}, \mathrm{A549}$, and LS411N cells (Supplementary Figure S6). For each cell line, we used a hierarchical, linear model to calculate the effect on cell cycle phase distribution across the four different ASO/siRNA assays assuming a random effect for each assay. In line with previous results, we observed a significant difference in cell cycle distribution for the $\mathrm{G} 1$ and $\mathrm{G} 2 / \mathrm{M}$ phases in $\mathrm{HaCaT}$ cells. A549 cells showed a significant difference in cell cycle distribution for the $\mathrm{S}$ phase, whereas for LS411N cells, the cell cycle distribution was significant for the G1 and S phases (Figure 2E).

While the siRNAs and ASO used affected cell cycle distribution in A549 cells, the phase distribution varied across assays, probably due to assay-specific off-target effects. The number of cells present in the G1 phase was reduced using ASO and in two out of three siRNAs, while there was a significant enrichment of cells in the $S$ phase across all four assays. Meanwhile the effect on the 
G2/M phase varied, with a reduction of cells present in the G2/M phase using ASO and siRNA $A 2$, no effect with siRNA A1, and an increase with siRNA A3 (Figure 2E).

The effect of knockdown was more consistent between different siRNAs and the ASO in LS411N cells. Interestingly, ASO and siRNA-mediated knockdown of SNHG26 had the opposite effect on phase distribution in LS411N cells as compared to what we observed in HaCaT and A549 cells, with a significant enrichment of cells in the $\mathrm{G} 1$ phase and a reduction of cells in the $\mathrm{S}$ phase across all four assays (Figure 2E). This implies that SNHG26 affects cell cycle through a different mechanism in LS411N, possibly related to cell-specific mechanisms and differences in the cells' epigenetic or mutational status.

Importantly, the effects of modulating SNHG26 expression were consistent between the different methods used. Unintended effects caused by non-specific binding are more or less frequent for siRNAs, ASO, and CRISPRi/a, but differ between methods (Stojic et al., 2018, Jackson et al., 2003). Such method-specific biases and off-target effects are therefore unlikely explanations of our results.

\section{SNHG26 regulates the expression of its neighbor gene TOMM7}

The mainly nuclear localization pattern as well as the appearance of bright foci we observed for SNHG26 may be consistent with an accumulation of transcripts at its site of transcription. Thus, we wondered whether SNHG26 regulates the expression of other genes from its location of transcription. To address this question, we used RT-qPCR to determine whether CRISPRi/a of SNHG26 affected the expression level of its neighbor mRNAs TOMM7 and FAM126A in HaCaT cells. We observed a reduction in the expression of TOMM7 using CRISPRi, and the opposite trend for CRISPRa. Meanwhile, CRISPRi did not affect the expression of FAM126A, whereas CRISPRa of SNHG26 increased the expression of FAM126A, although not significantly, due to large variation between replicates (Figure $3 \mathrm{~A}$ ).

To address whether SNHG26's effect on its neighboring genes was transcriptional or posttranscriptional, we first investigated TOMM7 and FAM126A expression following ASO-mediated knockdown of SNHG26. In both HaCaT and A549 cells, we observed a downregulation of TOMM7 expression (Figure 3B). We also observed a slight downregulation of FAM126A in response to ASOmediated knockdown in both cell lines, yet the effect was not significant. Second, we investigated whether CRISPRi/a of TOMM7 affected SNHG26 expression, reasoning that if SNHG26's effect was primarily post-transcriptional we should see no effect on SNHG26 expression. Indeed, CRISPRi/a mediated knockdown and upregulation of TOMM7 had no effect on the expression of SNHG26 (Figure 3C).

We further investigated whether downregulation of SNHG26 affected the chromatin state at the TSSs of TOMM7 and FAM126A. We used CRISPRi to knockdown SNHG26 in HaCaT cells followed by ChIP-qPCR of H3K4me3, H3K27me3, and EZH2. EZH2 was included as an additional marker for gene repression, as it is a part of the Polycomb Repressive Complex 2 (PRC2) where it catalyzes the addition of methyl groups to lysine 27 of histone 3 (Cao et al., 2002). Consistent with reduced transcriptional activity, we observed a reduction of H3K4me3 occupancy at the TSS of both TOMM7 and FAM126A, and a slight increase in H3K27me3 and EZH2, yet none were significant (Figure 3D).

Overall, the above results suggest that $S N H G 26$ is a post-transcriptional positive regulator of TOMM7, possibly through cis accumulation of SNHG26 RNA. 


\section{SNHG26 affects mitochondrial stress}

TOMM7 is a part of the TOM complex found in the mitochondrial membrane where it is involved in the transport of proteins into the mitochondria. TOMM7 probably acts by stabilizing PTEN-induced kinase 1 (PINK1) on the outer membrane of depolarized mitochondria where it recruits Parkin and activates its E3 ubiquitin ligase by phosphorylation. Impaired stabilization of PINK1 results in less activation of Parkin, which is necessary for the degradation of damaged mitochondria through mitophagy, and causes increased production of reactive oxygen species (ROS) and cell death (Pickrell and Youle, 2015). Due to the essential roles of mitochondria in cellular homeostasis, mitochondrial damage is associated with a broad spectrum of diseases (Palikaras et al., 2018). Results from a genome wide RNAi screen suggest that loss of TOMM7 blocks the accumulation of PINK1 on the outer mitochondrial membrane (OMM) and the recruitment of PARKIN in response to chemically depolarized OMM, yet the import of proteins through the TOM complex is not affected (Hasson et al., 2013, Sekine et al., 2019). Previous studies have shown that TOMM7 is a driver of cerebral angiogenesis, and TOMM7 deficiency affects mitochondrial stress in primary cultures of human brain microvascular endothelial cells and in vascular-specific transgenic zebrafish (Shi et al., 2018).

As SNHG26 regulates the expression of TOMM7, we sought out to examine whether SNHG26 induced growth inhibition was caused by the downregulation of TOMM7, due to increased ROS production and subsequent cell death. To address this question, we measured the level of mitochondrial ROS in response to CRISPRi/a of SNHG26 and TOMM7 in HaCaT cells. CRISPRimediated downregulation of $S N H G 26$ resulted in a significant increase of mitochondrial stress, and we observed an opposite trend for the CRISPRa-mediated upregulation of SNHG26 (Figure 3F). The increased mitochondrial stress after SNHG26 downregulation was validated by ASO-mediated knockdown of SNHG26 in HaCaT and A549 cells (Supplementary Figure S10). In contrast, there was no significant effect of CRISPRi/a-mediated modulation of TOMM7 on the level of mitochondrial stress (Figure 3F). Our results show that increasing and decreasing SNHG26 expression affect TOMM7 expression and mitochondrial stress, but that directly modulating TOMM7 expression has no effect on mitochondrial stress. Consequently, SNHG26 affects mitochondrial stress through a mechanism that is either independent off or synergistic with SNHG26's effect on TOMM7 expression.

\section{RNA sequencing identifies differentially expressed genes involved in cell cycle, DNA replication, and proliferation}

Whereas the above results showed that $S N H G 26$ is a positive regulator of its neighboring gene TOMM7, the results also suggested that SNHG26 has additional trans effects. Specifically, as SNHG26 is localized both as bright nuclear foci and as low-intensity spots, we reasoned that SNHG26 probably impacts diverse target genes post-transcriptionally by relocating or acting in trans from its site of transcription.

To identify such possible trans targets, we performed RNA-seq of CRISPRi and CRISPRa in $\mathrm{HaCaT}$ cell lines transduced with SNHG26-specific gRNA or a non-target control gRNA (Figure 4A). For CRISPRi and CRISPRa we identified a total of 1692 and 1268 differentially expressed genes with $p$ value $\leq 0.05$, respectively. Moreover, there were 110 differentially expressed genes with $p$-value < 0.05 in both CRISPRi vs. Control and CRISPRa vs. Control (Supplementary Figure S11). Of these, 61 genes were differential expressed in opposite directions in the CRISPRi compared with the CRISPRa experiments ( $p$-value $\leq 0.01$ ), including LATS1 (large tumor suppressor 1 ) and LIN52 (protein lin-52 homolog). 
As we expected targets of SNHG26 to be differentially affected in CRISPRi compared with CRISPRa of SNHG26, we did a separate interaction analysis to identify such genes. This analysis identified 1623 genes that were differentially expressed between CRISPRa vs. Control compared to CRISPRi vs. Control with $p$-value $\leq 0.05$, which included well-known cell cycle regulators such as TP53, CCNF (cyclin F), CDK8, CDKN2A (cyclin-dependent kinase inhibitor 2A), PLK5 (polo like kinase 5), and CCNDBP1 (cyclin D1 binding protein 1) (Figure 4B; Supplementary Dataset S1). The top five significant genes (adjusted $p$-value $\leq 0.05$, Figure $4 C$ ) were significantly enriched for $\mathrm{GO}$ terms related to cell cycle, including G1/S transition, G2/M checkpoints, and DNA replication (Figure 4D), which is in line with our data that demonstrates that SNHG26 affects cell cycle progression and proliferation.

Three of the five genes, MCM10 (minichromosome maintenance protein 10), CDCA7 (cell division cycle associated 7), and AC098934.1, have previously been described in the literature with growth promoting abilities (Gao et al., 2020, Park et al., 2008, Osthus et al., 2005). In our study, MCM10 was downregulated ( $\log _{2}$ fold change (LogFC -3.185) in CRISPRi cells transduced with gRNA targeting SNHG26 and upregulated (LogFC 2.058) in response to CRISPRa-mediated upregulation of SNHG26 compared to control. Another growth promoting protein included in the top five opposite expressed genes was CDCA7, which was also downregulated (LogFC -3.403) in response to CRISPRi and upregulated (LogFC 2.059) in response to CRISPRa of SNHG26. The IncRNA AC098934.1 (also known as RP11-480I12.5 and TUBAP5) was upregulated (LogFC in 2.909) in response to CRISPRi and downregulated (LogFC in -2.054) in response to CRISPRa of SNHG26. Meanwhile, AC126474.2 and CTAGE15 have unknown functions.

Several of the differentially expressed genes in both CRISPRi and CRISPRa are direct or indirect MYC responsive genes, including MCM10, CDCA7, TP53, CDKN2A, CCNF, and CDK8 (Yang et al., 2018, Prescott et al., 2001, Koch et al., 2007, Kang et al., 2020, Gill et al., 2013, Kidder et al., 2008, Phesse et al., 2014, Garcia-Gutierrez et al., 2019). SNHG26 was detected as a MYC-target in P493-6 human B-cells, where it was upregulated in response to MYC overexpression (Hart et al., 2014). A subsequent study found SNHG26 to be a direct transcriptional target of $M Y C$ and a driver of MYC-mediated proliferation in human lymphoid cell lines (Raffeiner et al., 2020). From our previous study on cell cycle synchronized HaCaT cells, the level of MYC in HaCaT cells peaked during the G2/M phase, similarly to the cell cycle profile of $S N H G 26$, demonstrating a positive correlation between their expression through the cell cycle phases (preprint: https://doi.org/10.1101/2021.02.12.430890). The MYC family of oncogenes consists of $c-M Y C, N$ $M Y C$, and $L-M Y C$, and is believed to regulate the transcription of about $15 \%$ of the genome. MYC regulates several of the positive cell cycle regulators including cyclins, CDKs and E2F transcription factors. Moreover, MYC is able to inhibit the activation of the cell cycle inhibitors p21 and p27, and is overexpressed in $60-70 \%$ of human cancers (Garcia-Gutierrez et al., 2019). Studies suggest cell cycleassociated functions of c-MYC for different cancer cells, including regulatory roles for the G1/S and G2/M phase transitions through different mechanisms (Felsher et al., 2000, Song et al., 2013, Yang et al., 2018).

Both MCM10 and CDCA7 were identified as cell cycle-associated genes in our previous study, with expression levels peaking during $\mathrm{G} 1 / \mathrm{S}$ phase (preprint: https://doi.org/10.1101/2021.02.12.430890). MCM10 is a known cell cycle-associated growth promoting protein that is required for proper DNA replication (Baxley and Bielinsky, 2017). MCM10 plays an essential role in initiation of DNA replication at replication origins and elongation by stabilizing DNA polymerase- $\alpha$ and its association to chromatin during DNA replication. 
Downregulation of MCM10 reduces the replication fork elongation rate. Moreover, MCM10 is a CDK substrate and is associated with chromatin in the late stage of replication initiation, although it is not necessary for the process (Chadha et al., 2016). MCM10 is often overexpressed in several cancers, and its expression is associated with tumor progression (Kang et al., 2020, Cui et al., 2018, Baxley and Bielinsky, 2017)). Moreover, MCM10 is listed as one of the top ranked cancer-associated genes in non-small-cell lung cancer (NSCLC) and breast cancer across different methods and from independent patient datasets (Wu et al., 2012). Depletion of MCM10 has been reported to induce G2/M cell cycle arrest (Park et al., 2008, Romani et al., 2015). A study identified MCM10 as upregulated by $M Y C N$ in neuroblastoma, where it stimulated cell cycle progression. Although the expression levels of $M C M 10$ and $M Y C N$ were highly correlated, there were no direct interaction between $M Y C N$ and the promoter of MCM10, suggesting that MCM10 is not a direct target of MYCN, or that MYCN binds outside the analyzed promoter region (Koppen et al., 2007). CDCA7 is frequently upregulated in human cancers, including breast- and colorectal cancer, where its expression may be used to predict prognosis and progression (Li et al., 2020, Ye et al., 2018). Moreover, CDCA7 is an E2F- and MYC responsive gene, and studies suggest that it contributes to MYC-mediated tumorigenesis, possibly by the direct association to MYC (Gill et al., 2013, Prescott et al., 2001, Osthus et al., 2005, Goto et al., 2006).

Our results show that SNHG26 is predominantly nuclear and affects gene expression both in cis and trans - characteristics shared by other IncRNAs involved in transcriptional regulation (Cabili et al., 2015). However, since SNHG26 also appears as extranuclear low-intensity spots, functions connected to the cytoplasm, such as SNHG26 encoding a small peptide, cannot be excluded. We also note that SNHG26 is host to snoRNA SNORD93, so CRISPR-mediated modulation of SNHG26 expression could also affect SNORD93's levels and thereby its targets. While it is less likely that siRNA- and ASO-mediated downregulation of SNHG26 affects SNORD93 expression, we cannot exclude this possibility.

In conclusion, downregulation of SNHG26 affects several cellular processes including cell cycle, metabolic rate, proliferation, mitochondrial stress, and gene expression in cis- and in trans, an effect that appears to be post-transcriptional and may be reversed by upregulation of SNHG26 expression. As SNHG26 is a direct MYC target gene, we propose that it affects cell cycle and proliferation through the regulation of downstream MYC-responsive genes, such as MCM10, CDCA7, TP53, CDKN2A, CCNF, and CDK8

\section{Material and Methods}

\section{Cell culture}

All cell lines used were obtained from the American Type Culture Collection (ATCC) and cultivated in a humidified incubator at $37^{\circ} \mathrm{C}$ in $5 \% \mathrm{CO}_{2}$. $\mathrm{HaCaT}$, a human keratinocyte cell line, $\mathrm{A} 549$, an adenocarcinoma human alveolar basal epithelial cell line, and Hek293T, a human epithelial kidney cell line, were all cultured in Dulbecco's modified Eagle's medium (DMEM) (Sigma-Aldrich, D6429) supplemented with 10\% fetal bovine serum (FBS) (Sigma-Aldrich, F7524) and 2 mM L-Glutamine (Sigma-Aldrich, G7513). For XTT viability and Mitosox assays we used DMEM without phenol red (Gibco, 21063-029). LS411N, a Dukes' type B colorectal carcinoma cell line, was cultivated in RPMI 1640 Medium (Gibco, A1049101) supplemented with 10\% FBS. All cell lines were sub-cultivated at least twice a week at about $70 \%$ confluence, and regularly tested for mycoplasma infections. 


\section{Single molecule RNA fluorescence in situ hybridization (RNA FISH)}

The software available through Stellaris Probedesigner was used to design the oligonucleotide sets. For the SNHG26 we used masking 4, length 20 and spacing 2, which resulted in 37 oligonucleotides. Stellaris ${ }^{\mathrm{TM}}$ probesets (Biosearch Technologies) were conjugated to a Quasar670 dye in the $3^{\prime}$ end. Hybridization and staining were performed as prescribed in the Stellaris protocol for adherent cells. We used GAPDH as a predesigned control. The probe sequences are listed in Supplementary Table S1.

\section{Imaging}

We used a Zeiss Laser TIRF 3 fluorescence microscope (Zeiss), equipped with a $\alpha$-Plan-Apochromat 100x/1.46 oil-immersion objective for imaging of the cells. A Zeiss $81 \mathrm{HE} \mathrm{DAPI/FITC/Rh/Cy5} \mathrm{filter} \mathrm{was}$ used, DAPI was excited by LED-module $365 \mathrm{~nm}$ (Zeiss Colibri) and Quasar670 was excited by $644 \mathrm{~nm}$ wavelength laser. The images were acquired by either a Hamamatsu EMCCD EMX2 or a Hamamatsu ORCA-Fusion camera at 16 bit and at a voxel size of $100 \times 100 \times 220 \mathrm{~nm}^{\wedge} 3$ (EMCCD) or $129 \times 129 \times$ $220 \mathrm{~nm}$ size (ORCA-Fusion). Image deconvolution was performed using SVI Huygenes Professional (version 18.10) and image analysis was done using Fiji (version 1.52t) (Schindelin et al., 2012). For the spot intensity analysis a circular region of interest (ROI) of 10 pixels was used for manually measuring the intensity of individual spots and a cut-off of 5000 was used to differentiate between bright and dim spots. Presented images are maximum intensity projections of 34 Z-stack slices (7.26 $\mu \mathrm{m})$ of the cell.

\section{Plasmids and cloning}

Lenti-sgRNA puro was a gift from Brett Stringer (Addgene plasmid \# 104990). We followed the Zhang labs protocol (https://media.addgene.org/data/plasmids/52/52961/52961-

attachment B3xTwla0bkYD.pdf) for guide RNA (gRNA) design and cloning of the gRNA between the two BsmBI restriction sites. The hU6-F (5'-GAGGGCCTATTTCCCATGATT-3') was used to sequence the RNA to validate gRNA insert. For CRISPRi we used pHR-SFFV-dCas9-BFP-KRAB (Gilbert et al., 2013), a gift from Stanley Qi \& Jonathan Weissman (Addgene plasmid \# 46911). For CRISPRa we used pXPR_120 with multiple activating domains VP64, P65 and Rta (Najm et al., 2018), a gift from John Doench \& David Root (Addgene plasmid \# 96917).

\section{Lentiviral production}

Hek293T cells were plated 24 hours before transfection with Lenti-sgRNA puro containing the different gRNAs or pHR-SFFV-dCas9-BFP-KRAB or PXPR_120 together with the packaging plasmids psPAX.2 and pMD2.G using Lipofectamine 2000 (Invitrogen ${ }^{\text {TM }}$, 11668019). Culture medium was replaced 7 hours after transfection to decrease toxicity. Fifty-five hours after transfection the viral supernatant was collected, centrifuged at $1800 \mathrm{~g}$ for $5 \mathrm{~min}$ at $4^{\circ} \mathrm{C}$, filtered through a $45 \mu \mathrm{M}$ filter, and stored at $-80^{\circ} \mathrm{C}$.

\section{Generating stable dCas9 expressing cell lines}

We performed a reverse transduction of both $\mathrm{HaCaT}$ and $\mathrm{A} 549$ cells by adding lentiviral pHR-SFFVdCas9-BFP-KRAB or pXPR_120 together with $8 \mu \mathrm{g} / \mathrm{ml}$ polybrene (Sigma-Aldrich, H9268) in DMEM, to generate CRISPRi and CRISPRa cell lines, respectively. The medium was replaced 48 hours after transduction, and $10 \mu \mathrm{g} / \mathrm{ml}$ blasticidin (Invivogen) was supplied to select for cells that had incorporated PXPR_120 into their genome. We changed the medium of PXPR_120 after three days, 
while selection was continued until all control cells had died, which took about five days. We kept the selection pressure on cells containing the activating construct PXPR_120 by supplying DMEM with $5 \mu \mathrm{g} / \mathrm{ml}$ blasticidin during sub-cultivating. We used a FACS Aria II cell sorter (BD Bioscience) to select for cells transduced with the inhibiting construct pHR-SFFV-dCas9-BFP-KRAB.

\section{Guide RNA (gRNA) design}

The E-CRISPR online tool (http://www.e-crisp.org/E-CRISP) was used for gRNA design [12]. The sequence targeted -50 to +200 base pairs (bp) relative to the transcriptional start site (TSS) of SNHG26 (>hg38_dna range=chr7:22854048-22854298). We determined the exact location of TSS using the Fantom5 genome browser (ZENBU 3.0.1) (Lizio et al., 2015, Lizio et al., 2019). We used the Basic local alignment Search Tool to avoid off-target effects. The sequences of different gRNAs are listed in Supplementary Table S2.

\section{gRNA transductions}

We transduced the CRISPRi/a modified cells with target-specific lentiviral gRNAs or a control gRNA together with $8 \mu \mathrm{g} / \mathrm{ml}$ polybrene 20 hours after seeding at approximately $50 \%$ confluence. The multiplicity of infection (MOI) was 2.1. To select for resistant cells that contained the gRNA, we added $2 \mu \mathrm{g} / \mathrm{ml}$ puromycin (Invivogen, ant-pr-1) to the growth media 24 hours after transduction. Cells were harvested 72 hours after selection started. We included gRNAs specific for MALAT1 and SLC4A1 as positive controls for CRISPRi and CRISPRa, respectively.

\section{Changes in cell cycle phase distribution are not caused by TOMM7}

To investigate whether the observed changes in cell cycle distribution in response to CRISPRi/a of SNHG26 is mediated through the regulation of TOMM7, we used CRISPRi/a to modulate the expression of TOMM7 in HaCaT cells, followed by cell cycle assays (Figure $3 \mathrm{E}$ ). We did not observe the same changes in cell cycle phase distribution as for SNHG26 (Figure 2D), suggesting SNHG26 is affecting the cell cycle through another mechanism.

\section{Short interfering (siRNA) and Antisense oligo (ASO)-mediated knockdown}

We transfected cells with siRNAs and/or Antisense LNA GapmeRs (Antisense oligo; ASOs) for a 20 $\mathrm{nM}$ final concentration using Lipofectamine RNAimax (Invitrogen ${ }^{\mathrm{TM}}, 13778030$ ) when seeded, according to the manufacturer's protocol. Cells were harvested after 48 and/or 72 hours after transfection at about $70 \%$ confluence. MISSION ${ }^{\circ}$ siRNA Universal Negative Control \#1 (Sigma, SIC001) and Negative control B Antisense LNA GapmeR (Qiagen, LG00000001) were used as controls for siRNAs and ASOs, respectively. The producers and sequences of siRNAs and ASOs are listed in Supplementary Table S3.

\section{Quantitative Real-Time PCR (RT-qPCR)}

To isolate total RNA, we used the mirVana miRNA Isolation Kit (Invitrogen ${ }^{\mathrm{TM}}$, AM1560) according to manufacturer's protocol, followed by DNase treatment with TURBO DNA-free ${ }^{\text {TM }}$ (Invitrogen ${ }^{\text {TM }}$, AM1907). We used NanoDrop ND-1000 UV-Vis Spectrophotometer to measure the RNA concentration and quality. RNA was converted to CDNA under standard conditions with random hexamer primers using TaqMan ${ }^{\text {TM }}$ Reverse Transcription reagents (Invitrogen ${ }^{\text {TM }}$, N8080234). Quantitative RT-PCR reactions were prepared with SYBR select master mix (Applied Biosystems, 4472919). The sequences of the different primers used are listed in Supplementary Table S4. 
Relative expression levels were calculated using the comparative $C_{T}$ method $\left(2^{-\Delta \Delta C T}\right.$ method (Livak and Schmittgen, 2001)), and expression data were normalized to GAPDH.

\section{Viability assay}

To investigate how up- and downregulation of SNHG26 affected viability, measured as the level of metabolic activity, we performed TACS XTT Cell viability Assay (R\&D Systems ${ }^{\mathrm{TM}}$, 4891025K). HaCaT cells with the repressing domain and the activating domains were transduced with target-specific lentiviral gRNAs or a non-target control gRNA. Cells were seeded in triplicates for each condition in a 96-well tray 96 hours after transduction. We measured absorbance 24, 48, and 72 hours after seeding, 4 hours after XTT was added, following the manufacturer's protocol. XTT viability assay was also performed with HaCaT cells transfected with SNHG26-specific siRNA or a non-target control siRNA as described in the section above. We measured absorbance 48 hours after seeding, 4 hours after XTT was added, following the manufacturer's protocol.

\section{Proliferation assay}

We performed cell counting using Moxi z mini automated cell counter (ORFLO Technologies) to investigate how ASO-mediated knockdown of SNHG26 affected proliferation in HaCaT, A549, and LS411N cells. Cells were seeded in triplicates for each condition in a 24-well tray and counted 48 and 72 hours after transfection. Each well was washed twice with preheated PBS and trypsinated for 8$10 \mathrm{~min}$ before the cells were resuspended in preheated growth medium and counted. We applied a two-tailed, paired Student's $t$-test to test whether the cell number was significantly different ( $p$ value $<0.05$ ) between cells transfected with a non-target negative control ASO and a target-specific ASO in three or more independent experiments.

\section{Cell cycle and fluorescence-activated cell sorting (FACS) analysis}

For the cell cycle experiments cells were harvested 48 hours after siRNA-mediated transfection, and 96 hours after gRNA transduction. We washed twice with preheated PBS and trypsinated for 8-10 min before collecting the cells using ice-cold PBS supplemented with 3\% FBS. The cells were then centrifuged at $4^{\circ} \mathrm{C}$ for $5 \mathrm{~min}$, and the supernatant was carefully removed. For FACS analysis, cells were fixed in ice-cold $100 \%$ methanol and stored at $4^{\circ} \mathrm{C}$ until DNA measurement. The cells were washed with cold PBS and incubated with $200 \mu \mathrm{l}$ of DNase-free RNAse A in PBS $(100 \mu \mathrm{g} / \mathrm{ml})$ for 30 min at $37^{\circ} \mathrm{C}$ before DNA staining with $200 \mu$ of Propidium lodide (PI, Sigma) $(50 \mu \mathrm{g} / \mathrm{ml})$ at $37^{\circ} \mathrm{C}$ for 30 min. We used BD FACS Canto flow cytometer (BD Biosciences) for cell cycle analyses. The excitation maximum of $\mathrm{PI}$ is $535 \mathrm{~nm}$ and the emission maximum is $617 \mathrm{~nm}$. The blue laser ( $488 \mathrm{~nm}$ ) excited PIstained cells and the PI fluorescence was detected in the Phycoerythrin PE channel ( $578 \mathrm{~nm})$. Cell cycle fractions were determined by using the FlowJo software.

\section{Chromatin Immunoprecipitation (ChIP)}

$\mathrm{HaCaT}$ cells were trypsinated and harvested with PBS containing $3 \% \mathrm{FBS}$ and washed twice with PBS (RT, room temperature). We counted the cells, and $3 \times 10^{6}$ cells were added to a final volume of 500 $\mu \mathrm{l}$ PBS. For crosslinking we added $13.5 \mu \mathrm{l}$ formaldehyde for a final concentration of $1 \%$, vortexed gently, and incubated for 10 minutes at RT. To stop the crosslinking we used $50 \mu \mathrm{l} 1.25 \mathrm{M}$ glycine for a final concentration of $0.125 \mathrm{M}$, vortexed gently and incubated for $5 \mathrm{~min}$ at RT. Cells were then washed twice with cold PBS, centrifuged at $3000 \mathrm{rpm}$ for 5 minutes before we resuspended the cell pellet in $1 \mathrm{ml}$ cold RIPA buffer (10 mM Tris pH 8.0, 1 mM EDTA, $140 \mathrm{mM} \mathrm{NaCl}, 1 \%$ Triton X-100, 0.1\% 
SDS, 0.1\% Na-Deoxycholate) supplemented with protease inhibitors and $125 \mathrm{mM}$ glycine. Samples were snap-frozen in liquid nitrogen and stored at $-80^{\circ} \mathrm{C}$. Later, cells were thawed and incubated in a RIPA buffer (with $0.5 \%$ SDS) on ice for $15 \mathrm{~min}$. The cells were vortexed before adding a RIPA buffer without SDS for a final concentration of $0.1 \%$ SDS in a volume of $300 \mu \mathrm{l}$. We sonicated the cells using a Bioruptor ${ }^{\circledR}$ Standard with refrigerated sonication bath for 6-10 cycles of $30 \mathrm{sec}$ ON and $30 \mathrm{sec}$ OFF at high setting. Then the samples were briefly vortexed and debris was removed by centrifuging at top speed at $4^{\circ} \mathrm{C}$ for $15 \mathrm{~min}$. Soluble chromatin supernatant equivalent to $6 \mu \mathrm{g}$ per IP was precleared using $20 \mu \mathrm{l}$ of a 1:1 mix of protein A and protein G Dynabeads (Invitrogen). Overnight IP was performed using $1 \mu \mathrm{g}$ of anti-H3K4me3 (Diagenode, C1541003-50), $2 \mu \mathrm{g}$ anti-H3K27me3 (Diagenode, C15410195), and $2.5 \mu \mathrm{g}$ anti-enhancer of zeste homolog 2 (EZH2) (Diagenode, C15200180).

Antibody-protein complexes were immunoprecipitated with protein A/G Dynabeads for 3 hours at $4^{\circ} \mathrm{C}$ with rotation. Then the samples were washed for five minutes per wash with rotation; five times with $500 \mu \mathrm{l}$ RIPA buffer supplemented with protease inhibitors, once with $500 \mu \mathrm{LiCl}$ wash buffer (250 mM LiCl, $10 \mathrm{mM}$ Tris pH 8.0, 1 mM EDTA, 0.5\% NP-40, 0.5\% Na-Deoxycholate) supplemented with protease inhibitors, and once in $500 \mu \mathrm{l} \mathrm{TE}$ buffer (10 mM Tris-HCl pH 8.0, $1 \mathrm{mM}$ EDTA). The beads were resuspended in $100 \mu \mathrm{l}$ TE buffer and immunoprecipitated DNA was reverse cross-linked by adding $1 \mu \mathrm{l}$ RNaseA [10 mg/ml] and incubated at $37^{\circ} \mathrm{C}$ for $30 \mathrm{~min}$. Then we added $2.5 \mu \mathrm{l} 20 \%$ SDS and $5 \mu \mathrm{l}$ Proteinase $\mathrm{K}[10 \mathrm{mg} / \mathrm{ml}]$ and incubated at $55^{\circ} \mathrm{C}$ for 1 hour, followed by purification using QIAquick PCR purification kit (Qiagen, 28104).

\section{Chromatin Immunoprecipitation qPCR (ChIP-qPCR)}

For accurate fragment assessment, the shared chromatin was analyzed on a $1.5 \%$ agarose gel. Fragment size was optimized to be 200-500 bp. PCR primers were designed in the TSS region for the SNHG26 neighbor genes; Translocase of Outer Mitochondrial Membrane 7 (TOMM7) and Family with Sequence Similarity 126 Member A (FAM126A) (Supplementary Table S5). As a control for successful IP, qPCR was performed using human positive and negative control qPCR primer sets from Active Motif (Supplementary Table S6). Furthermore, qPCR was performed on immunoprecipitated material and input chromatin. We added $2 \mu \mathrm{l}$ ChIP DNA and $500 \mathrm{nM}$ of each primer to SYBR Select Master Mix (Applied Biosystems) in three technical replicates. Target values from all qPCR samples were normalized with matched input DNA using the percent input method [100*2^ (Adjusted input Ct (IP)]. The relative expression of TOMM7 and FAM126A was normalized against GAPDH.

\section{Mitosox}

We used MitoSOX ${ }^{\mathrm{TM}}$ Red Mitochondrial Superoxide Indicator (Thermo Fisher Scientific, M36008) to detect mitochondrial superoxide/reactive oxygen species (ROS formation). The MitoSOX red reagent permeates the cell membrane and selectively targets mitochondria where it is oxidized by superoxide. We seeded $40000 \mathrm{cl} / \mathrm{ml}$ of HaCaT cells in a 24-well plate and transduced with gRNAs as previously described. After selection, the cells were washed twice with PBS and labeled with $5 \mu \mathrm{M}$ Mitosox supplied in DMEM without phenol red (Thermo Fisher Scientific, 21063029) for 30 minutes at $37^{\circ} \mathrm{C}$, protected from light. Then we washed the cells twice with pre-heated PBS and trypsinated for about 8 minutes before neutralizing with $500 \mu$ I DMEM without phenol red. The cells were centrifuged and re-suspended in $300 \mu \mathrm{l}$ cold PBS, followed by BD FACS Canto flow cytometer (BD Bioscience) to detect the level of fluorescence with excitation/emission of $488 / 578$. We used $50 \mu \mathrm{M}$ Menadione as a positive control and no stained cells as a negative control. 


\section{Total RNA sequencing (RNA-seq)}

Total RNA was isolated using the mirVana miRNA Isolation Kit (ThermoFisher Scientific, AM1560), according to the manufacturer's protocol. RNA concentration was measured on a Qubit (Thermo fisher), whereas integrity and stability of the RNA samples were assessed by using an Agilent 2100 Bioanalyzer (Agilent Technologies). The ribosomal RNA (rRNA) was removed using RiboCop rRNA Depletion Kit for Human/Mouse/Rat V2 (Lexogen), followed by preparation of RNA-seq libraries using the CORALL total RNA library prep (Lexogen), according to the manufacturer's instructions. The samples were sequenced on an Illumina NextSeq HighOutput v2.5 flow cell using the Illumina NextSeq 500 Sequencing System.

\section{RNA-seq data analysis}

FASTQ files were filtered and trimmed (fastp v0.20.0) and transcript counts were generated using quasi alignment (Salmon v1.3.0) to the transcriptome reference sequence (Ensembl, GRCh38 release 92). We imported the transcript sequences into the $R$ statistical software and aggregated them to gene counts using the tximport (v1.14.0) bioconductor package. To compare gene expression between samples, the genes with expression of less than 1 count per million in at least $50 \%$ of the samples were filtered out. The count matrices were transformed using bioconductor package limma (Ritchie et al., 2015) combined with voom transformation (Law et al., 2014). In the limma framework, gene expression was modelled as a function of four binary variables representing cell line (CRISPRi/a) combined with treatment (SNH26 or control gRNA). Three contrasts were analyzed to identify differentially expressed genes: (i) differences between gRNA treatment in CRISPRi, (ii) in CRISPRa, and (iii) and interactions between gRNA treatments in CRISPRi and CRISPRa (i.e. differences between difference (i) and (ii)). Differentially expressed genes were identified using the topTable function of limma and Benjamini-Hochberg method was used to correct for multiple testing, and genes with $p$-values $<0.05$ were considered significantly differentially expressed.

\section{Acknowledgement}

This work was supported by the Norwegian Cancer Society (grant number 2278701) and the Research Council of Norway (grant number 230338). The library preparation and sequencing were provided by the Genomics Core Facility (GCF), Norwegian University of Science and Technology (NTNU). GCF is funded by the Faculty of Medicine and Health Sciences at NTNU and Central Norway Regional Health Authority. The light microscopy was provided by the Cellular and Molecular Imaging Core Facility (CMIC), NTNU. CMIC is funded by the Faculty of Medicine at NTNU and Central Norway Regional Health Authority.

\section{Author contribution}

HS designed and performed all imaging and wet lab experiments, contributed with statistical analysis, and wrote the manuscript. SAH contributed with statistical analysis, generated the figures, and was a major contributor in editing the manuscript. KC analyzed the RNA-seq data. NBL performed all FACS analysis. PAA contributed with the planning and design of CRISPR experiments. BS contributed to the planning of RNA FISH experiments and performed the image analysis. PS contributed to the study design, supervised the project, and edited the manuscript. All authors read and approved the final manuscript. 


\section{Declaration of interest}

The authors declare that they have no competing interests.

\section{Data availability}

The RNA-seq dataset generated and analyzed during the current study is available in the European Nucleotide Archive (https://www.ebi.ac.uk/ena/) under the accession number of: PRJEB43155

\section{Supplementary Data}

Supplementary file 1: Supplementary Figures and Tables

Supplementary dataset 1: A list of 1623 genes that were differentially expressed ( $p$-value $<0.05$ ) in CRISPRa vs. CRISPRi in HaCaT cells.

\section{References}

BAO, Z., ZHANG, W. \& DONG, D. 2017. A potential prognostic IncRNA signature for predicting survival in patients with bladder urothelial carcinoma. Oncotarget, 8, 10485-10497.

BAXLEY, R. M. \& BIELINSKY, A. K. 2017. Mcm10: A Dynamic Scaffold at Eukaryotic Replication Forks. Genes (Basel), 8.

BOHMDORFER, G. \& WIERZBICKI, A. T. 2015. Control of Chromatin Structure by Long Noncoding RNA. Trends Cell Biol, 25, 623-32.

BOUKAMP, P., PETRUSSEVSKA, R. T., BREITKREUTZ, D., HORNUNG, J., MARKHAM, A. \& FUSENIG, N. E. 1988. Normal keratinization in a spontaneously immortalized aneuploid human keratinocyte cell line. J Cell Biol, 106, 761-71.

BRIFFA, R., UM, I., FARATIAN, D., ZHOU, Y., TURNBULL, A. K., LANGDON, S. P. \& HARRISON, D. J. 2015. Multi-Scale Genomic, Transcriptomic and Proteomic Analysis of Colorectal Cancer Cell Lines to Identify Novel Biomarkers. PLoS One, 10, e0144708.

CABILI, M. N., DUNAGIN, M. C., MCCLANAHAN, P. D., BIAESCH, A., PADOVAN-MERHAR, O., REGEV, A., RINN, J. L. \& RAJ, A. 2015. Localization and abundance analysis of human IncRNAs at single-cell and single-molecule resolution. Genome Biology, 16, 20.

CAO, R., WANG, L., WANG, H., XIA, L., ERDJUMENT-BROMAGE, H., TEMPST, P., JONES, R. S. \& ZHANG, Y. 2002. Role of histone H3 lysine 27 methylation in Polycomb-group silencing. Science, 298, 1039-43.

CHADHA, G. S., GAMBUS, A., GILLESPIE, P. J. \& BLOW, J. J. 2016. Xenopus Mcm10 is a CDK-substrate required for replication fork stability. Cell Cycle, 15, 2183-2195.

CHEN, L. L. 2016. Linking Long Noncoding RNA Localization and Function. Trends Biochem Sci, 41, 761-772.

CUI, F., HU, J., NING, S., TAN, J. \& TANG, H. 2018. Overexpression of MCM10 promotes cell proliferation and predicts poor prognosis in prostate cancer. Prostate, 78, 1299-1310.

FAY, M. M. \& ANDERSON, P. J. 2018. The Role of RNA in Biological Phase Separations. J Mol Biol, 430, 4685-4701.

FELSHER, D. W., ZETTERBERG, A., ZHU, J., TLSTY, T. \& BISHOP, J. M. 2000. Overexpression of MYC causes p53-dependent G2 arrest of normal fibroblasts. Proc Natl Acad Sci U S A, 97, 10544-8.

GAO, X., LAI, Y., ZHANG, Z., MA, Y., LUO, Z., LI, Y., YANG, C., LU, G. \& LI, J. 2020. Long Non-coding RNA RP11-480I12.5 Promotes the Proliferation, Migration, and Invasion of Breast Cancer Cells Through the miR-490-3p-AURKA-Wnt/beta-Catenin Axis. Front Oncol, 10, 948.

GARCIA-GUTIERREZ, L., DELGADO, M. D. \& LEON, J. 2019. MYC Oncogene Contributions to Release of Cell Cycle Brakes. Genes (Basel), 10. 
bioRxiv preprint doi: https://doi.org/10.1101/2021.02.22.432245; this version posted February 23, 2021. The copyright holder for this preprint (which was not certified by peer review) is the author/funder. All rights reserved. No reuse allowed without permission.

GARDNER, P. P., FASOLD, M., BURGE, S. W., NINOVA, M., HERTEL, J., KEHR, S., STEEVES, T. E., GRIFFITHS-JONES, S. \& STADLER, P. F. 2015. Conservation and losses of non-coding RNAs in avian genomes. PLoS One, 10, e0121797.

GILBERT, L. A., LARSON, M. H., MORSUT, L., LIU, Z., BRAR, G. A., TORRES, S. E., STERN-GINOSSAR, N., BRANDMAN, O., WHITEHEAD, E. H., DOUDNA, J. A., LIM, W. A., WEISSMAN, J. S. \& QI, L. S. 2013. CRISPR-mediated modular RNA-guided regulation of transcription in eukaryotes. Cell, $154,442-51$.

GILL, R. M., GABOR, T. V., COUZENS, A. L. \& SCHEID, M. P. 2013. The MYC-associated protein CDCA7 is phosphorylated by AKT to regulate MYC-dependent apoptosis and transformation. Mol Cell Biol, 33, 498-513.

GOTO, Y., HAYASHI, R., MURAMATSU, T., OGAWA, H., EGUCHI, I., OSHIDA, Y., OHTANI, K. \& YOSHIDA, K. 2006. JPO1/CDCA7, a novel transcription factor E2F1-induced protein, possesses intrinsic transcriptional regulator activity. Biochim Biophys Acta, 1759, 60-8.

HART, J. R., ROBERTS, T. C., WEINBERG, M. S., MORRIS, K. V. \& VOGT, P. K. 2014. MYC regulates the non-coding transcriptome. Oncotarget, 5, 12543-54.

HASSON, S. A., KANE, L. A., YAMANO, K., HUANG, C. H., SLITER, D. A., BUEHLER, E., WANG, C., HEMAN-ACKAH, S. M., HESSA, T., GUHA, R., MARTIN, S. E. \& YOULE, R. J. 2013. High-content genome-wide RNAi screens identify regulators of parkin upstream of mitophagy. Nature, 504, 291-5.

HU, A. X., HUANG, Z. Y., ZHANG, L. \& SHEN, J. 2017. Potential prognostic long non-coding RNA identification and their validation in predicting survival of patients with multiple myeloma. Tumour Biol, 39, 1010428317694563.

JACKSON, A. L., BARTZ, S. R., SCHELTER, J., KOBAYASHI, S. V., BURCHARD, J., MAO, M., LI, B., CAVET, G. \& LINSLEY, P. S. 2003. Expression profiling reveals off-target gene regulation by RNAi. Nat Biotechnol, 21, 635-7.

JIANG, C., LI, Y., ZHAO, Z., LU, J., CHEN, H., DING, N., WANG, G., XU, J. \& LI, X. 2016. Identifying and functionally characterizing tissue-specific and ubiquitously expressed human IncRNAs. Oncotarget, 7, 7120-33.

KANG, P., HAN, Z., LIAO, Z., ZHANG, H., JIA, W. \& TIAN, Y. 2020. Knockdown of MCM10 Gene Impairs Glioblastoma Cell Proliferation, Migration and Invasion and the Implications for the Regulation of Tumorigenesis. J Mol Neurosci, 70, 759-768.

KIDDER, B. L., YANG, J. \& PALMER, S. 2008. Stat3 and c-Myc genome-wide promoter occupancy in embryonic stem cells. PLoS One, 3, e3932.

KITAGAWA, M., KITAGAWA, K., KOTAKE, Y., NIIDA, H. \& OHHATA, T. 2013. Cell cycle regulation by long non-coding RNAs. Cell Mol Life Sci, 70, 4785-94.

KNUTSEN, T., PADILLA-NASH, H. M., WANGSA, D., BARENBOIM-STAPLETON, L., CAMPS, J., MCNEIL, N., DIFILIPPANTONIO, M. J. \& RIED, T. 2010. Definitive molecular cytogenetic characterization of 15 colorectal cancer cell lines. Genes Chromosomes Cancer, 49, 204-23.

KOCH, H. B., ZHANG, R., VERDOODT, B., BAILEY, A., ZHANG, C. D., YATES, J. R., 3RD, MENSSEN, A. \& HERMEKING, H. 2007. Large-scale identification of c-MYC-associated proteins using a combined TAP/MudPIT approach. Cell Cycle, 6, 205-17.

KOPPEN, A., AIT-AISSA, R., KOSTER, J., VAN SLUIS, P. G., ORA, I., CARON, H. N., VOLCKMANN, R., VERSTEEG, R. \& VALENTIJN, L. J. 2007. Direct regulation of the minichromosome maintenance complex by MYCN in neuroblastoma. Eur J Cancer, 43, 2413-22.

LAW, C. W., CHEN, Y., SHI, W. \& SMYTH, G. K. 2014. voom: Precision weights unlock linear model analysis tools for RNA-seq read counts. Genome Biol, 15, R29.

LI, S., HUANG, J., QIN, M., ZHANG, J. \& LIAO, C. 2020. High expression of CDCA7 predicts tumor progression and poor prognosis in human colorectal cancer. Mol Med Rep, 22, 57-66.

LIANG, J., WEN, J., HUANG, Z., CHEN, X. P., ZHANG, B. X. \& CHU, L. 2019. Small Nucleolar RNAs: Insight Into Their Function in Cancer. Front Oncol, 9, 587. 
bioRxiv preprint doi: https://doi.org/10.1101/2021.02.22.432245; this version posted February 23, 2021. The copyright holder for this preprint (which was not certified by peer review) is the author/funder. All rights reserved. No reuse allowed without permission.

LIU, X. D., XIE, D. F., WANG, Y. L., GUAN, H., HUANG, R. X. \& ZHOU, P. K. 2019. Integrated analysis of IncRNA-mRNA co-expression networks in the alpha-particle induced carcinogenesis of human branchial epithelial cells. Int J Radiat Biol, 95, 144-155.

LIVAK, K. J. \& SCHMITTGEN, T. D. 2001. Analysis of relative gene expression data using real-time quantitative PCR and the 2(-Delta Delta C(T)) Method. Methods, 25, 402-8.

LIZIO, M., ABUGESSAISA, I., NOGUCHI, S., KONDO, A., HASEGAWA, A., HON, C. C., DE HOON, M., SEVERIN, J., OKI, S., HAYASHIZAKI, Y., CARNINCI, P., KASUKAWA, T. \& KAWAJI, H. 2019. Update of the FANTOM web resource: expansion to provide additional transcriptome atlases. Nucleic Acids Res, 47, D752-D758.

LIZIO, M., HARSHBARGER, J., SHIMOJI, H., SEVERIN, J., KASUKAWA, T., SAHIN, S., ABUGESSAISA, I., FUKUDA, S., HORI, F., ISHIKAWA-KATO, S., MUNGALL, C. J., ARNER, E., BAILLIE, J. K., BERTIN, N., BONO, H., DE HOON, M., DIEHL, A. D., DIMONT, E., FREEMAN, T. C., FUJIEDA, K., HIDE, W., KALIYAPERUMAL, R., KATAYAMA, T., LASSMANN, T., MEEHAN, T. F., NISHIKATA, K., ONO, H., REHLI, M., SANDELIN, A., SCHULTES, E. A., T HOEN, P. A., TATUM, Z., THOMPSON, M., TOYODA, T., WRIGHT, D. W., DAUB, C. O., ITOH, M., CARNINCI, P., HAYASHIZAKI, Y., FORREST, A. R., KAWAJI, H. \& CONSORTIUM, F. 2015. Gateways to the FANTOM5 promoter level mammalian expression atlas. Genome Biol, 16, 22.

MARCHESE, F. P., RAIMONDI, I. \& HUARTE, M. 2017. The multidimensional mechanisms of long noncoding RNA function. Genome Biol, 18, 206.

NAJM, F. J., STRAND, C., DONOVAN, K. F., HEGDE, M., SANSON, K. R., VAIMBERG, E. W., SULLENDER, M. E., HARTENIAN, E., KALANI, Z., FUSI, N., LISTGARTEN, J., YOUNGER, S. T., BERNSTEIN, B. E., ROOT, D. E. \& DOENCH, J. G. 2018. Orthologous CRISPR-Cas9 enzymes for combinatorial genetic screens. Nat Biotechnol, 36, 179-189.

OSTHUS, R. C., KARIM, B., PRESCOTT, J. E., SMITH, B. D., MCDEVITT, M., HUSO, D. L. \& DANG, C. V. 2005. The Myc target gene JPO1/CDCA7 is frequently overexpressed in human tumors and has limited transforming activity in vivo. Cancer Res, 65, 5620-7.

PALIKARAS, K., LIONAKI, E. \& TAVERNARAKIS, N. 2018. Mechanisms of mitophagy in cellular homeostasis, physiology and pathology. Nat Cell Biol, 20, 1013-1022.

PARK, J. H., BANG, S. W., KIM, S. H. \& HWANG, D. S. 2008. Knockdown of human MCM10 activates G2 checkpoint pathway. Biochem Biophys Res Commun, 365, 490-5.

PATTERSON, D. G., ROBERTS, J. T., KING, V. M., HOUSEROVA, D., BARNHILL, E. C., CRUCELLO, A., POLSKA, C. J., BRANTLEY, L. W., KAUFMAN, G. C., NGUYEN, M., SANTANA, M. W., SCHILLER, I. A., SPICCIANI, J. S., ZAPATA, A. K., MILLER, M. M., SHERMAN, T. D., MA, R., ZHAO, H., ARORA, R., COLEY, A. B., ZEIDAN, M. M., TAN, M., XI, Y. \& BORCHERT, G. M. 2017. Human snoRNA-93 is processed into a microRNA-like RNA that promotes breast cancer cell invasion. NPJ Breast Cancer, 3, 25.

PENG, K. J., WANG, J. H., SU, W. T., WANG, X. C., YANG, F. T. \& NIE, W. H. 2010. Characterization of two human lung adenocarcinoma cell lines by reciprocal chromosome painting. Dongwuxue Yanjiu, 31, 113-21.

PHESSE, T. J., MYANT, K. B., COLE, A. M., RIDGWAY, R. A., PEARSON, H., MUNCAN, V., VAN DEN BRINK, G. R., VOUSDEN, K. H., SEARS, R., VASSILEV, L. T., CLARKE, A. R. \& SANSOM, O. J. 2014. Endogenous c-Myc is essential for p53-induced apoptosis in response to DNA damage in vivo. Cell Death Differ, 21, 956-66.

PICKRELL, A. M. \& YOULE, R. J. 2015. The roles of PINK1, parkin, and mitochondrial fidelity in Parkinson's disease. Neuron, 85, 257-73.

PRESCOTT, J. E., OSTHUS, R. C., LEE, L. A., LEWIS, B. C., SHIM, H., BARRETT, J. F., GUO, Q., HAWKINS, A. L., GRIFFIN, C. A. \& DANG, C. V. 2001. A novel c-Myc-responsive gene, JPO1, participates in neoplastic transformation. J Biol Chem, 276, 48276-84.

RAFFEINER, P., HART, J. R., GARCIA-CABALLERO, D., BAR-PELED, L., WEINBERG, M. S. \& VOGT, P. K. 2020. An MXD1-derived repressor peptide identifies noncoding mediators of MYC-driven cell proliferation. Proc Natl Acad Sci U S A, 117, 6571-6579. 
bioRxiv preprint doi: https://doi.org/10.1101/2021.02.22.432245; this version posted February 23, 2021. The copyright holder for this preprint (which was not certified by peer review) is the author/funder. All rights reserved. No reuse allowed without permission.

RITCHIE, M. E., PHIPSON, B., WU, D., HU, Y., LAW, C. W., SHI, W. \& SMYTH, G. K. 2015. limma powers differential expression analyses for RNA-sequencing and microarray studies. Nucleic Acids Res, 43, e47.

ROMANI, B., SHAYKH BAYGLOO, N., AGHASADEGHI, M. R. \& ALLAHBAKHSHI, E. 2015. HIV-1 Vpr Protein Enhances Proteasomal Degradation of MCM10 DNA Replication Factor through the Cul4-DDB1[VprBP] E3 Ubiquitin Ligase to Induce G2/M Cell Cycle Arrest. J Biol Chem, 290, 17380-9.

SCHINDELIN, J., ARGANDA-CARRERAS, I., FRISE, E., KAYNIG, V., LONGAIR, M., PIETZSCH, T., PREIBISCH, S., RUEDEN, C., SAALFELD, S., SCHMID, B., TINEVEZ, J. Y., WHITE, D. J., HARTENSTEIN, V., ELICEIRI, K., TOMANCAK, P. \& CARDONA, A. 2012. Fiji: an open-source platform for biological-image analysis. Nat Methods, 9, 676-82.

SEKINE, S., WANG, C., SIDERIS, D. P., BUNKER, E., ZHANG, Z. \& YOULE, R. J. 2019. Reciprocal Roles of Tom7 and OMA1 during Mitochondrial Import and Activation of PINK1. Mol Cell, 73, 10281043 e5.

SHI, D., QI, M., ZHOU, L., LI, X., NI, L., LI, C., YUAN, T., WANG, Y., CHEN, Y., HU, C., LIANG, D., LI, L., LIU, Y., LI, J. \& CHEN, Y. H. 2018. Endothelial Mitochondrial Preprotein Translocase Tomm7Rac1 Signaling Axis Dominates Cerebrovascular Network Homeostasis. Arterioscler Thromb Vasc Biol, 38, 2665-2677.

SINGH, D. K. \& PRASANTH, K. V. 2013. Functional insights into the role of nuclear-retained long noncoding RNAs in gene expression control in mammalian cells. Chromosome Res, 21, 695711.

SONG, A., YE, J., ZHANG, K., SUN, L., ZHAO, Y. \& YU, H. 2013. Lentiviral vector-mediated siRNA knockdown of c-MYC: cell growth inhibition and cell cycle arrest at G2/M phase in Jijoye cells. Biochem Genet, 51, 603-17.

STOJIC, L., LUN, A. T. L., MANGEI, J., MASCALCHI, P., QUARANTOTTI, V., BARR, A. R., BAKAL, C., MARIONI, J. C., GERGELY, F. \& ODOM, D. T. 2018. Specificity of RNAi, LNA and CRISPRi as loss-of-function methods in transcriptional analysis. Nucleic Acids Res, 46, 5950-5966.

WANG, K. C. \& CHANG, H. Y. 2011. Molecular mechanisms of long noncoding RNAs. Mol Cell, 43, 904-14.

WILLIAMS, G. T. \& FARZANEH, F. 2012. Are snoRNAs and snoRNA host genes new players in cancer? Nat Rev Cancer, 12, 84-8.

WU, C., ZHU, J. \& ZHANG, X. 2012. Integrating gene expression and protein-protein interaction network to prioritize cancer-associated genes. BMC Bioinformatics, 13, 182.

YANG, Y., XUE, K., LI, Z., ZHENG, W., DONG, W., SONG, J., SUN, S., MA, T. \& LI, W. 2018. c-Myc regulates the CDK1/cyclin $\mathrm{B} 1$ dependentG2/M cell cycle progression by histone $\mathrm{H} 4$ acetylation in Raji cells. Int J Mol Med, 41, 3366-3378.

YE, L., LI, F., SONG, Y., YU, D., XIONG, Z., LI, Y., SHI, T., YUAN, Z., LIN, C., WU, X., REN, L., LI, X. \& SONG, L. 2018. Overexpression of CDCA7 predicts poor prognosis and induces EZH2mediated progression of triple-negative breast cancer. Int J Cancer, 143, 2602-2613.

ZIMTA, A. A., TIGU, A. B., BRAICU, C., STEFAN, C., IONESCU, C. \& BERINDAN-NEAGOE, I. 2020. An Emerging Class of Long Non-coding RNA With Oncogenic Role Arises From the snoRNA Host Genes. Front Oncol, 10, 389. 


\section{Figures}

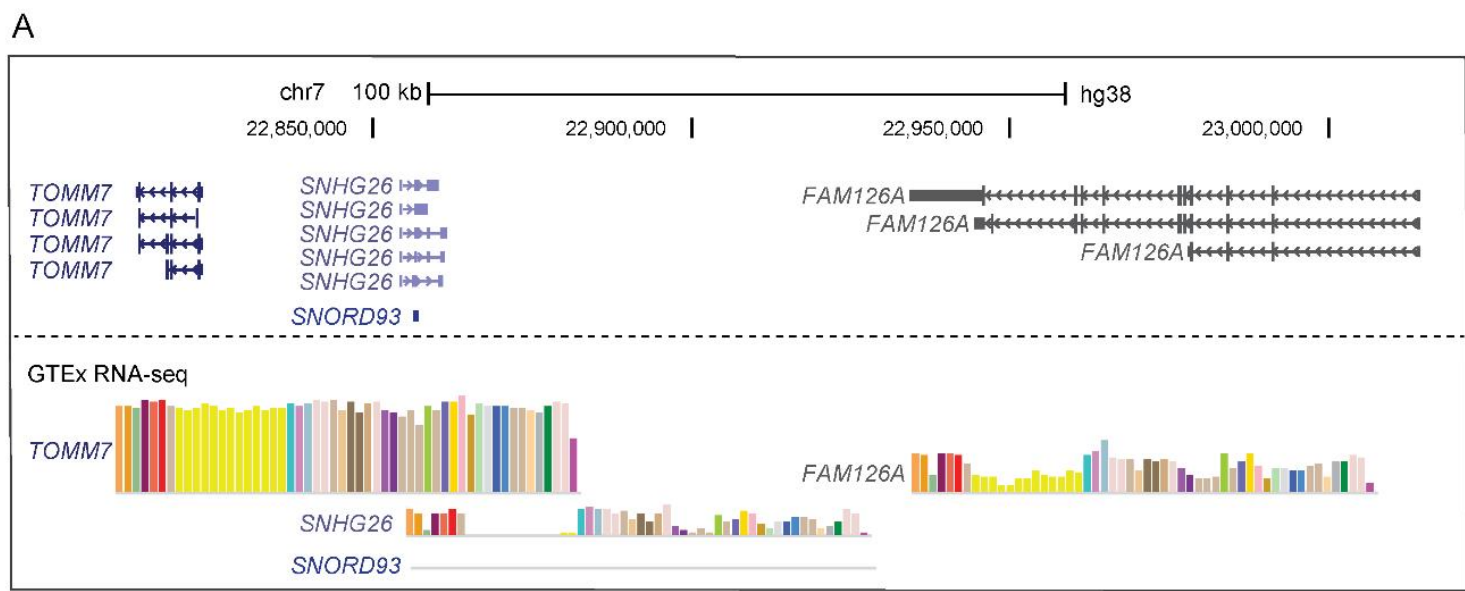

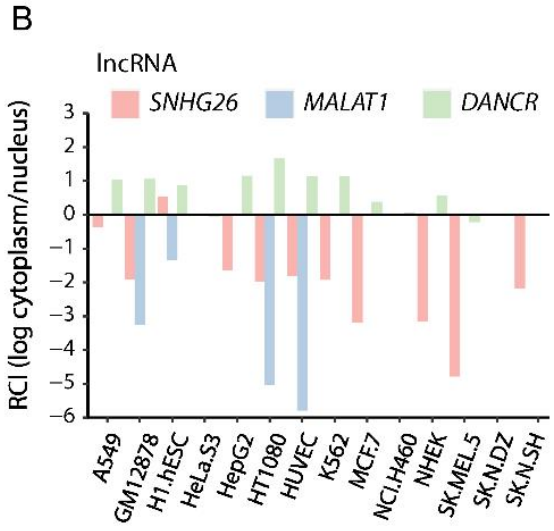

D

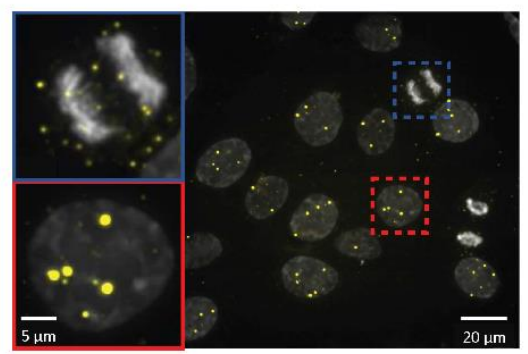

C

HaCaT

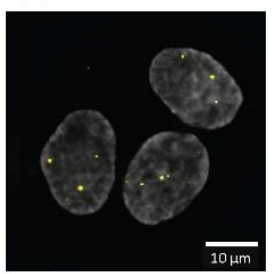

A549

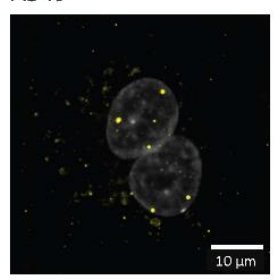

LS411N

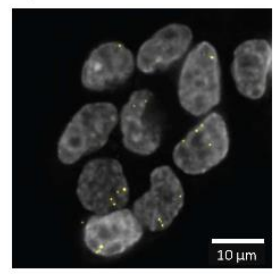

E

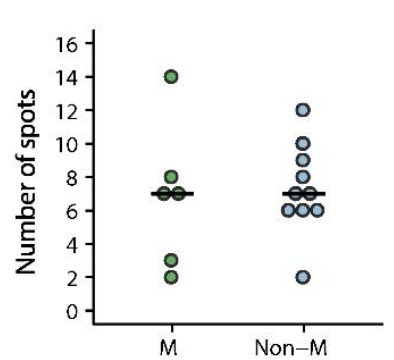

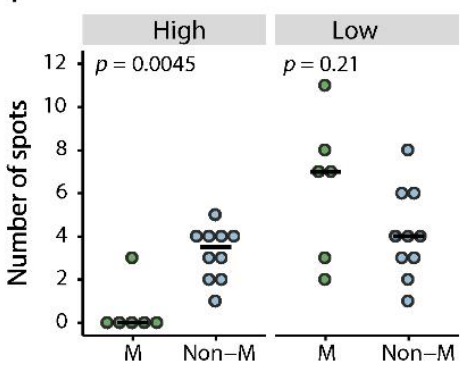

Figure 1. SNHG26 is mainly localized in the nucleus as bright foci, and as nuclear and cytoplasmic low-intensity spots.

(A) The genomic loci of SNHG26 from the UCSC Genome Browser (https://genome.ucsc.edu/). Tissue expression data (transcript per kilobase million, TPM) are from the GTEx project. (B) The subcellular localization of SNHG26, MALAT1, and DANCR. Data are from the IncAtlas (https://Incatlas.crg.eu/) and display the subcellular localization based on the RCI of RNA between cytoplasm and nucleus. Values $<0$ indicate nuclear enrichment. (C) The localization of SNHG26 (yellow) in fixed HaCaT, A549, and LS411N cells with DAPI-stained nuclei (grey) were visualized by using SNHG26-specific Stellaris ${ }^{\mathrm{TM}}$ probe sets conjugated to a Quasar670 dye in the $3^{\prime}$ end. Presented images are maximum intensity projections of $34 \mathrm{Z}$-stack slices $(7.26 \mu \mathrm{m})$ of the cell. (D) A representative image of mitotic HaCaT cells. (E) The total number of spots co-localized with the DNA in 6 mitotic (M) and 10 non-mitotic (non-M) HaCaT cells. Crossbars represent median values. For the spot intensity analysis, a circular $\mathrm{ROI}$ of 10 pixels was used for manually measuring the intensity of individual spots that were associated with the DNA and a cut-off of 5000 was used to differentiate between high- and low- 
bioRxiv preprint doi: https://doi.org/10.1101/2021.02.22.432245; this version posted February 23, 2021. The copyright holder for this preprint (which was not certified by peer review) is the author/funder. All rights reserved. No reuse allowed without permission.

intensity spots. A Wilcoxon rank sum test was used to compare the distribution in mitotic and nonmitotic cells ( $p$-value $=0.869)$. $(F)$ The total number of high- and low-intensity spots co-localized with DNA in 6 mitotic (M) and 10 non-mitotic (non-M) HaCaT cells. Crossbars represent median values. A Wilcoxon rank sum test was used to compare the distribution in mitotic and non-mitotic cells; highintensity spots $p$-value $=0.0045$, low-intensity spots $p$-value $=0.208$. 
A

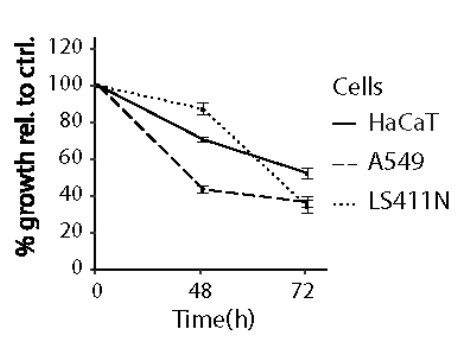

D

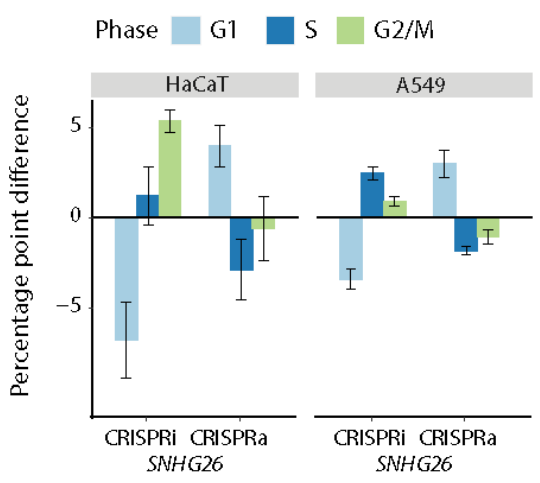

B

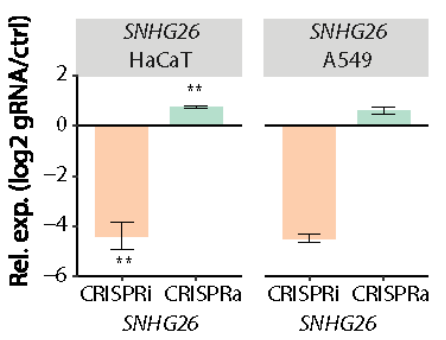

C

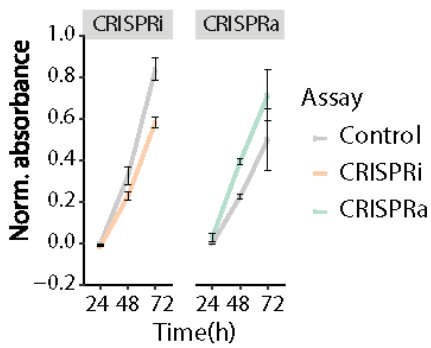

E

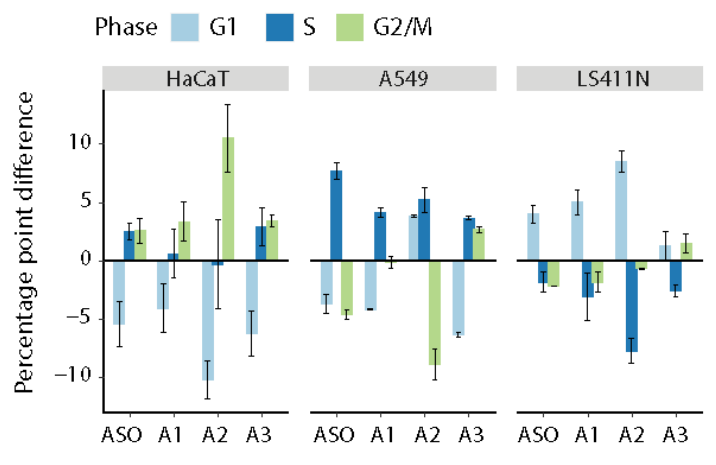

Figure 2. SNHG26 affects proliferation, metabolic activity, and cell cycle phase distribution.

(A) Effect of ASO-mediated knockdown of SNHG26 on proliferation in HaCaT, A549, and LS411N cells. Data are the number of cells following ASO treatment relative to control treated cells (percentage of control) as measured by cell counting. Bars and error bars are mean and standard error of mean (SEM) of three or more independent replicates. Significant differences were determined by Student's $t$-test (unpaired, two-tailed), assuming equal variances (all $p$-values $* * p \leq 0.01$ ), except LS411N $48 \mathrm{~h}$ with $p=0.058)$ ). (B) The relative expression level of $S N H G 26$ as measured by RT-qPCR in response to CRISPRi/a of SNHG26 in HaCaT and A549 cells. Data are presented as fold change expressions of cells transduced with SNHG26-specific gRNA relative to control gRNA. Bars and error bars are mean and SEM of two or more independent replicates. Significant differences were determined by Student's $t$ test (unpaired, two-tailed), assuming equal variances $\left({ }^{*} p \leq 0.05 ;{ }^{*} p \leq 0.01\right)$. (C) Effect of CRISPRi/a of SNHG26 on metabolic activity in HaCaT cells as measured by XTT. Data are presented as normalized absorbance $\left(A_{465 \mathrm{~nm}}-\mathrm{A}_{630 \mathrm{~nm}}\right)$ for cells transduced with SNHG26-specific gRNA and control gRNA. Bars and error bars are mean and SEM of three independent replicates. Significant differences were determined by Student's $t$-test (paired, two-tailed), assuming equal variances (CRISPRi $48 \mathrm{~h} p=$ $0.167,72 \mathrm{~h} p=0.061$; CRISPRa $48 \mathrm{~h} p=0.004,72 \mathrm{~h} p=0.027$ ). (D-E) The distribution of cells in $\mathrm{G} 1, \mathrm{~S}$, and G2/M cell cycle phases in response to (D) CRISPRi/a modulation of SNHG26 in HaCaT and A549 cells and (E) ASO and siRNA (A1, A2, A3) mediated knockdown of SNHG26 in HaCaT, A549, and LS411N cells. Data are the difference in percentages of $G 1, S$, and $G 2 / M$ cells between cells transduced/transfected with target-specific gRNA/siRNA/ASO to those transduced/transfected with a control gRNA/siRNA/ASO. (D) Bars and error bars are mean and SEM of three independent replicates. ANOVA $p$-values were calculated from a hierarchical, linear model: HaCaT: G1: 7e-04, S: 0.120, and G2/M: 0.031; A549: G1: 5.02e-08, S: 5.83e-06, and G2/M: 0.007. (E) Bars and error bars are mean and SEM of two or more independent replicates. ANOVA $p$-values were calculated from a hierarchical, linear model: HaCaT : G1: 7.96e-06, S: 0.275, and G2/M: 0.0002; A549 : G1: 0.068, S: 0.001, and G2/M: 0.056; LS4111N: G1: 6.05e-05, S: 0.0005, and G2/M: 0.387. 
A

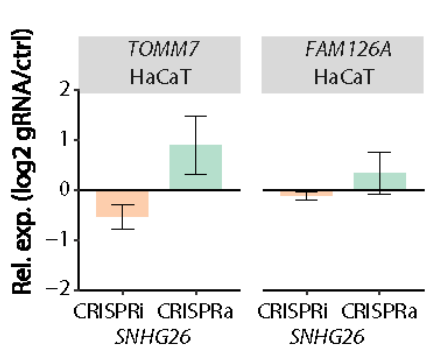

$\mathrm{B}$

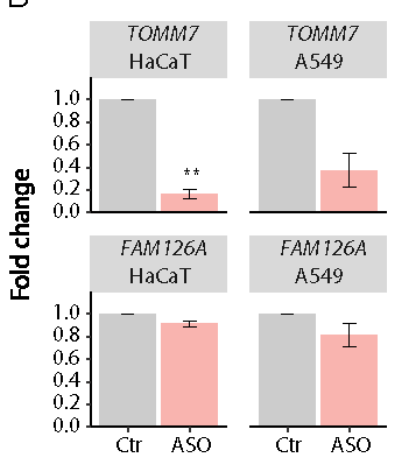

$E$

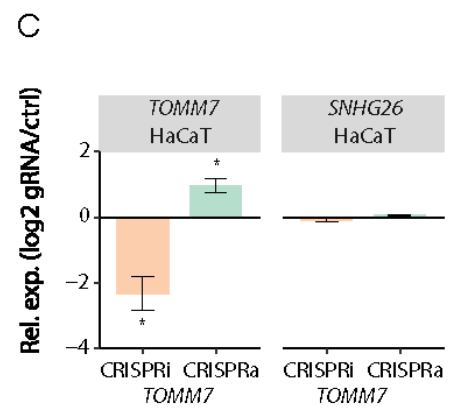

$\mathrm{F}$
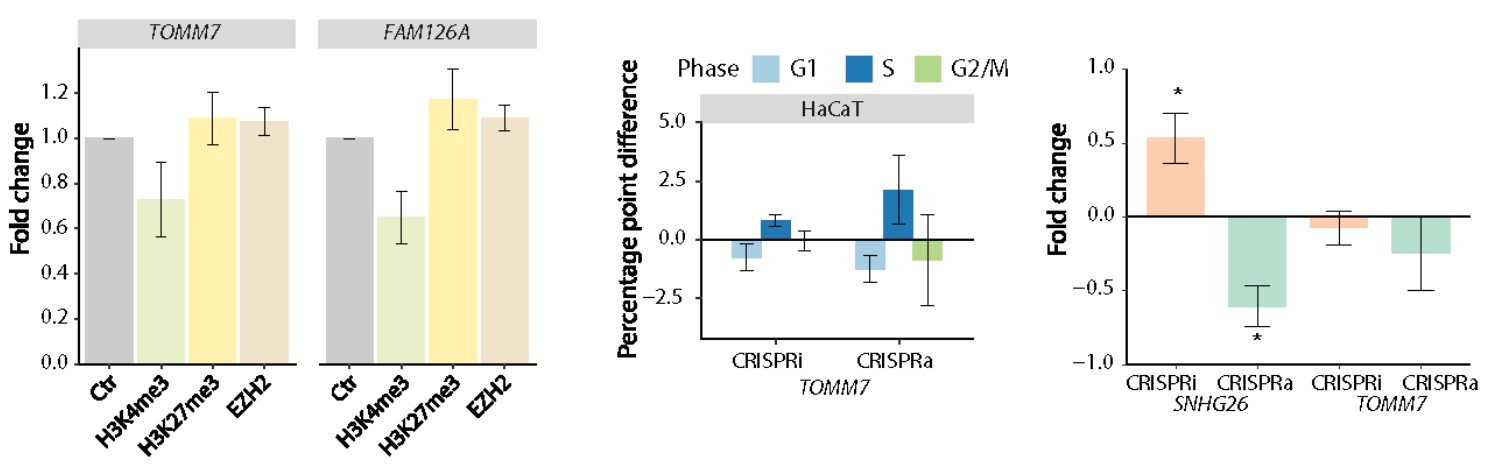

Figure 3. SNHG26 affects the expression of neighbor genes and mitochondrial stress

(A) The relative expression levels of TOMM7 and FAM126 as measured by RT-qPCR in response to CRISPRi/a of SNHG26 in HaCaT cells. Data are presented as fold change expressions of cells transduced with target-specific gRNA relative to control gRNA. Bars and error bars are mean and SEM of three independent replicates ( $n=2$ for CRISPRa FAM126A). $P$-values were calculated by Student's t-test, (unpaired, two-tailed) assuming equal variances (TOMM7 $p=0.06$ and $p=0.175$; FAM126 $p=0.24$ and $p=0.47$ for CRISPRi and CRISPRa, respectively). (B) The relative expression of TOMM7 and FAM126 as measured by RT-qPCR in HaCaT and A549 cells. Data are presented as fold change expressions of target genes following ASO treatment relative to control-treated cells. Bars and error bars are mean and SEM of three independent replicates. Significant differences were determined by Student's $t$-test, (unpaired, two-tailed) assuming equal variances ( ${ }^{* *} p \leq 0.01$, TOMM7 $p=0.003$ and $p=0.052$; FAM126 $p=0.085$ and $p=0.212$ in HaCaT and A549, respectively). (C) The relative expression level of TOMM7 and SNHG26 as measured by RT-qPCR in response to CRISPRi/a of TOMM7 in HaCaT cells. Data are presented as fold change expressions of cells transduced with target-specific gRNA relative to control gRNA. Bars and error bars are mean and SEM of three independent replicates. Significant differences were determined by Student's $t$-test, (unpaired, twotailed) assuming equal variances $\left({ }^{*} p \leq 0.05\right)$. (D) We used ChIP-qPCR to evaluate the effect of CRISPRi of SNHG26 on the level of H3K4me3, H3K27me3, and EZH2 at the TSS of TOMM7 and FAM126A in HaCaT cells. Bars and error bars are mean and SEM of three independent replicates. $P$ values were calculated by Student's t-test, (unpaired, two-tailed) assuming equal variances (TOMM7 $p=0.245, p=0.519, p=0.338$; FAM126 $p=0.09, p=0.326, p=0.243$, for H3K4me3, H3K27me3, and EZH2, respectively). (E) The distribution of cells in $\mathrm{G1}, \mathrm{S}$, and $\mathrm{G} 2 / \mathrm{M}$ cell cycle phases in response to CRISPRi/a of TOMM7 in HaCaT cells. Data are the difference in percentages of $\mathrm{G1}, \mathrm{S}$, and G2/M cells between cells transduced with target-specific gRNA to those transduced with a control gRNA. Bars and error bars are mean and SEM of three independent replicates. (F) We used Mitosox and FACS to determine whether CRISPRi/a-mediated modulation of SNHG26 and TOMM7 expression affected 
bioRxiv preprint doi: https://doi.org/10.1101/2021.02.22.432245; this version posted February 23, 2021. The copyright holder for this preprint (which was not certified by peer review) is the author/funder. All rights reserved. No reuse allowed without permission.

mitochondrial stress in $\mathrm{HaCaT}$ cells. Data are presented as fold change fluorescence intensity of cells transduced with target-specific gRNA relative to control gRNA. Bars and error bars are mean and SEM of three or more independent replicates. Significant differences were determined by Student's $t$-test (unpaired, two-tailed), assuming equal variances $\left({ }^{*} p \leq 0.05\right)$. 

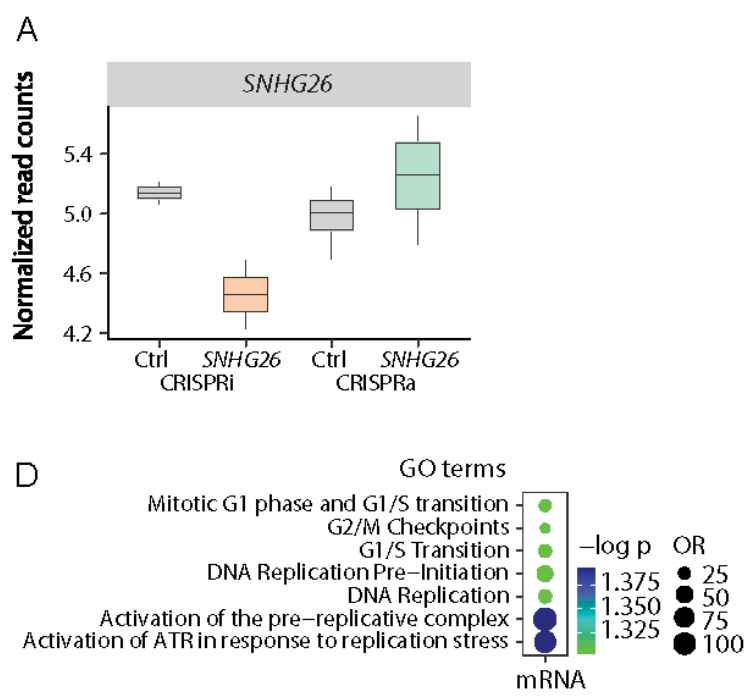

B

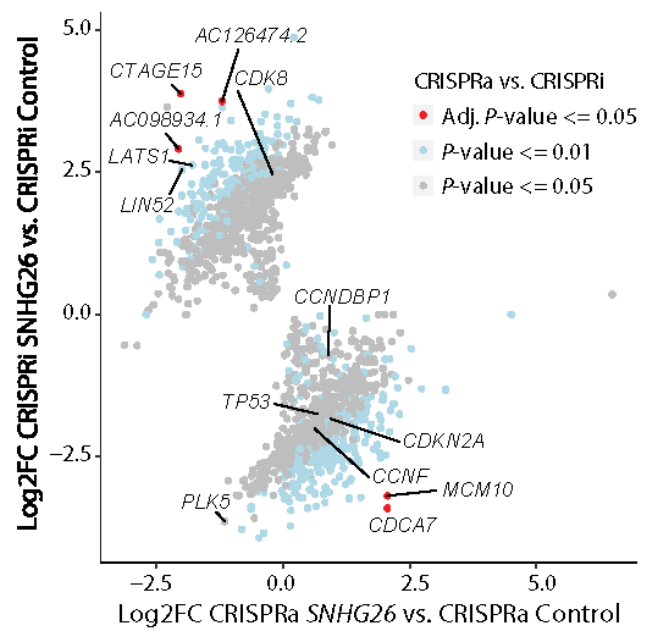

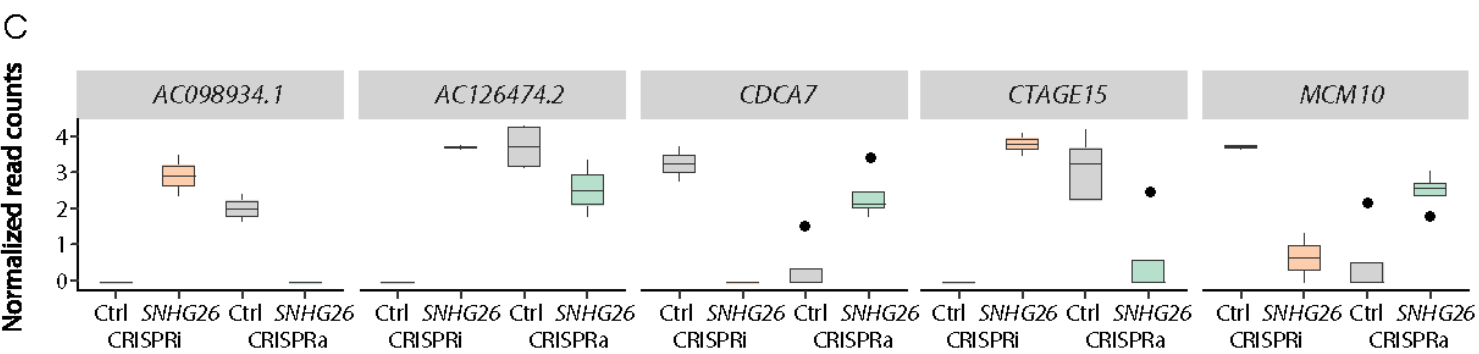

Figure 4. Total RNA-seq of CRISPRi/a modified HaCaT cell lines identify differentially expressed genes with functions connected to cell cycle and proliferation.

(A) RNA-seq expression level of SNHG26 in CRISPRi ( $n=2)$ and CRISPRa ( $n=4)$ modified HaCaT cells transduced with a SNHG26-specific gRNA compared to a non-specific gRNA control. Data are presented as normalized read counts. (B) A total of 1623 genes were differentially affected in CRISPRa vs. CRISPRi with $p$-value $<0.05$. They are colored according to their $p$-values and interesting genes are labelled. (C) The expression of the top five significant genes that were differentially expressed in the opposite direction in CRISPRa compared to CRISPRi. Data are presented as normalized read counts with adjusted $p$-value $<0.05$. (D) GO enrichment analysis for the top five significant genes that were differentially expressed in the opposite direction in CRISPRa compared to CRISPRi. The results show enrichment of cell cycle related GO terms. 


\section{Supplementary Figures}

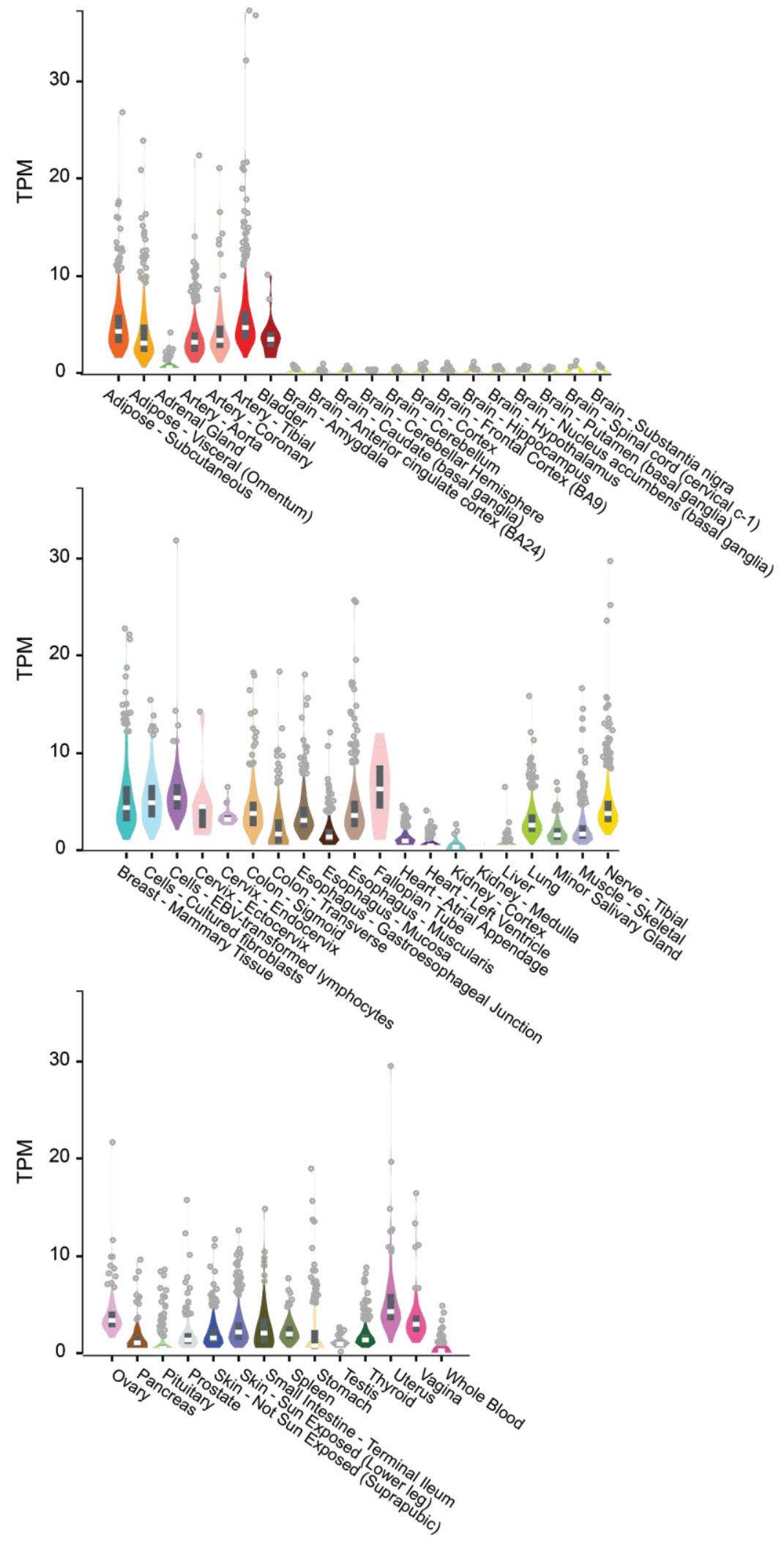

Supplementary Figure S1: Tissue expression (transcript per kilobase million, TPM) for SNHG26 (ENSG00000228649) from the Genotype-Tissue Expression (GTEx) project. 


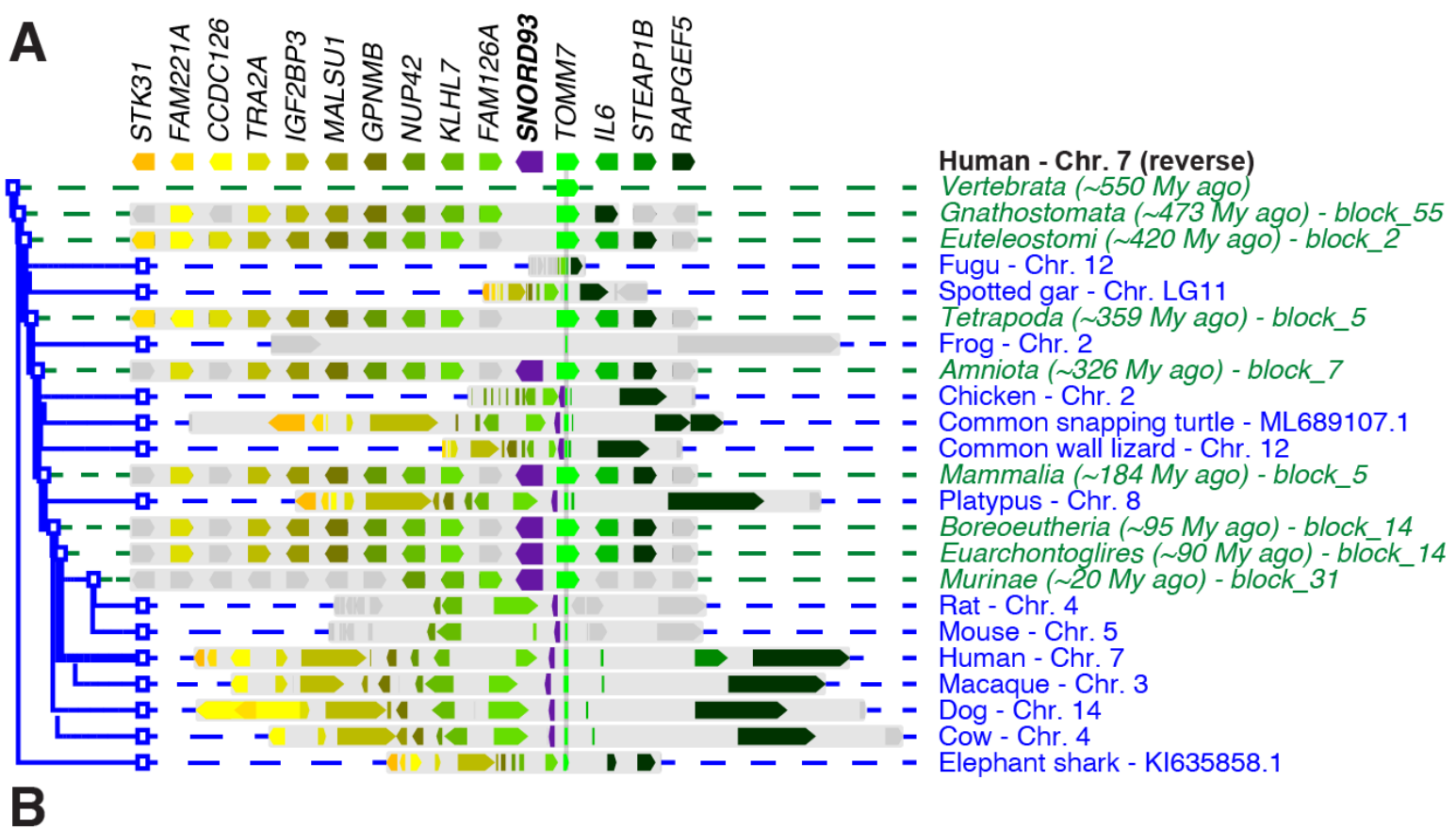

Chr. 7

(forward)

Homo sapiens (GRCh38.p13)

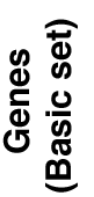

Ac005682
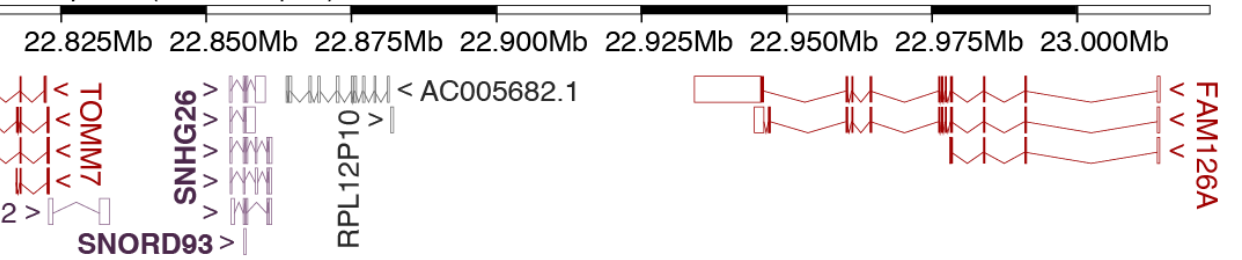

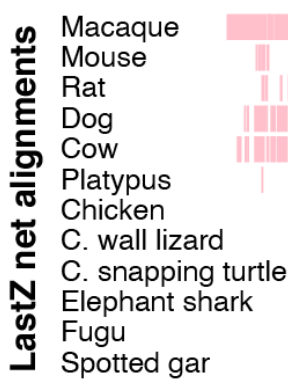

Protein coding gene RNA gene

Pseudogene

Conserved block

Supplementary Figure S2: The TOMM7-SNORD93-FAM126A locus is conserved in Amniota.

(A) Evolutionary conservation of genes in the locus. The view is centered on TOMM7, which is conserved in Vertebrata, and shows conservation of 14 neighboring human genes (color coded) in syntenic blocks (light gray) from selected species (blue) and ancestors (green). Genes in species are shown on a comparable genomic scale; genes in ancestors are shown as schematics. Other genes than those that are homologous to the 15 human genes from the locus are shown in grey. Data from Genomicus [1], modified to include SNORD93 conservation. (B) Overview of the human TOMM7SNORD93-FAM126A locus. "Genes" show transcripts from the GENCODE Basic set (Ensembl release 102); "LastZ net alignments" show conserved sequence blocks in the species from (A). 
bioRxiv preprint doi: https://doi.org/10.1101/2021.02.22.432245; this version posted February 23, 2021. The copyright holder for this preprint (which was not certified by peer review) is the author/funder. All rights reserved. No reuse allowed without permission.

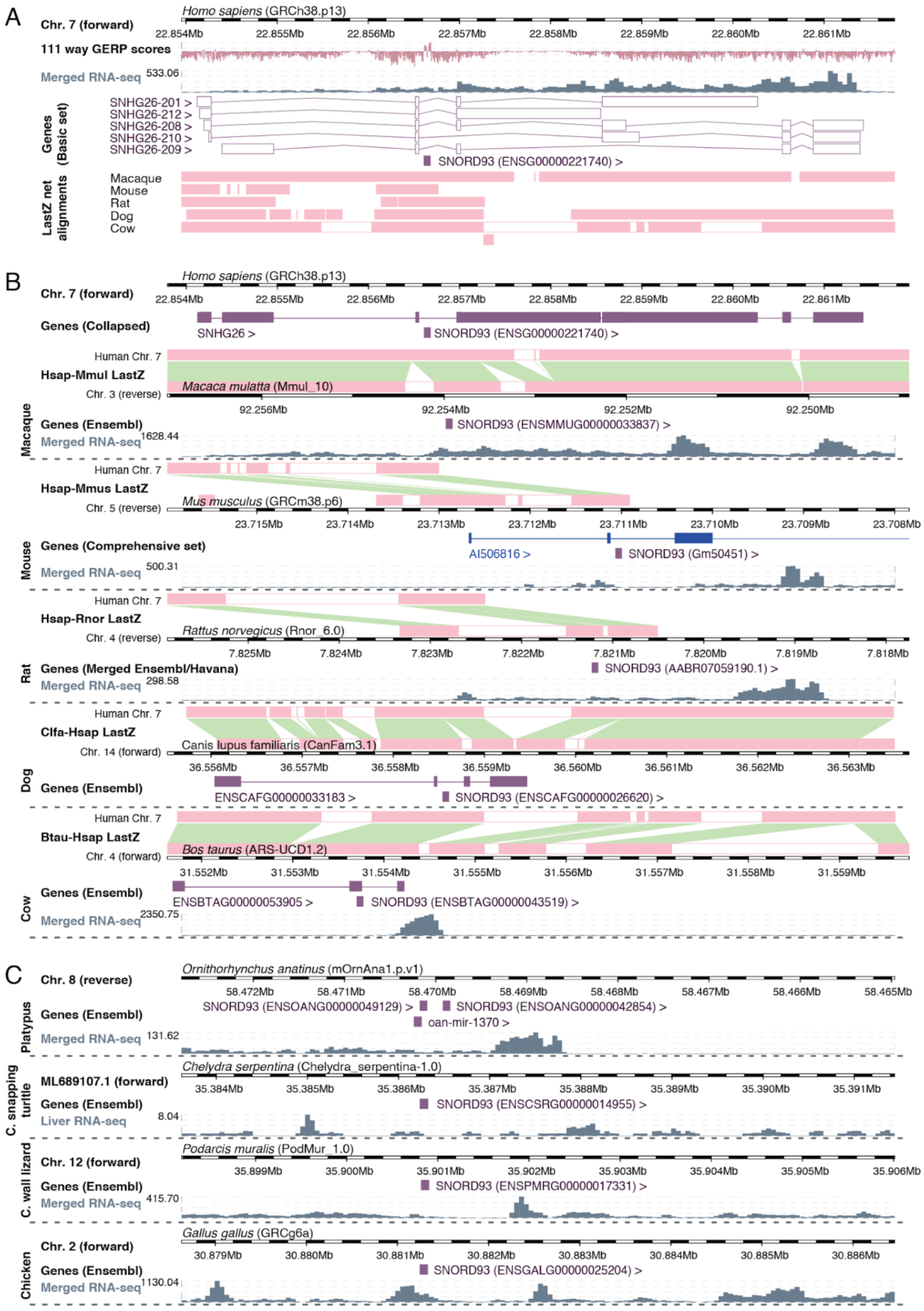

Supplementary Figure S3: Comparative genomics and RNA-seq data indicate conserved sequence and expression for SNHG26. (A) Overview of the human SNHG26 locus. The genome browser tracks show Genomic Evolutionary Rate Profiling (GERP) scores, RNA-seq read coverage from the Human 
bioRxiv preprint doi: https://doi.org/10.1101/2021.02.22.432245; this version posted February 23, 2021. The copyright holder for this preprint (which was not certified by peer review) is the author/funder. All rights reserved. No reuse allowed without permission.

BodyMap 2.0 project (ArrayExpress ID: E-MTAB-513), transcripts from the GENCODE Basic set (Ensembl release 102), and sequence blocks that are conserved in the species from Figure S2A. The genomic blocks containing SNHG26 exons 1-3 are largely conserved in all five species, whereas the last exons appear lost in rodents. (B) Sequence block conservation (pairwise LastZ maps), annotated genes (Genes), and RNA-seq read coverage (RNA-seq) within the SNHG26 homologous regions for the species in (A). Mouse, dog, and cow each have an annotated non-coding RNA (ncRNA) mapping to the SNHG26 homologous regions. Each species's RNA-seq data show transcription within the locus. (C) Annotated genes (Genes) and RNA-seq read coverage (RNA-seq) in the genomic regions surrounding the SNORD93 homologues in platypus, chicken, turtle, and lizard. Each species's RNAseq data show transcription within the overall locus.

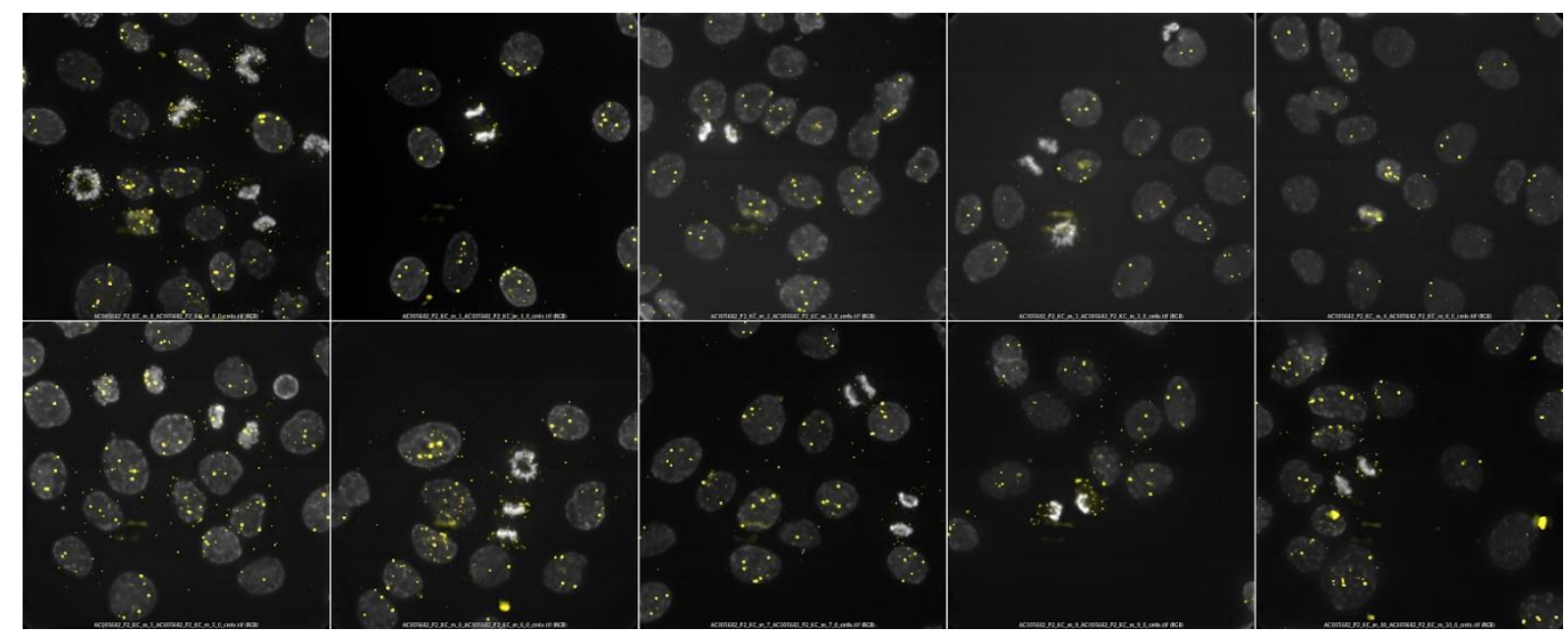

Supplementary Figure S4: Mitotic HaCaT cells. The localization of SNHG26 (yellow) in mitotic fixed HaCaT cells stained with DAPI (grey).

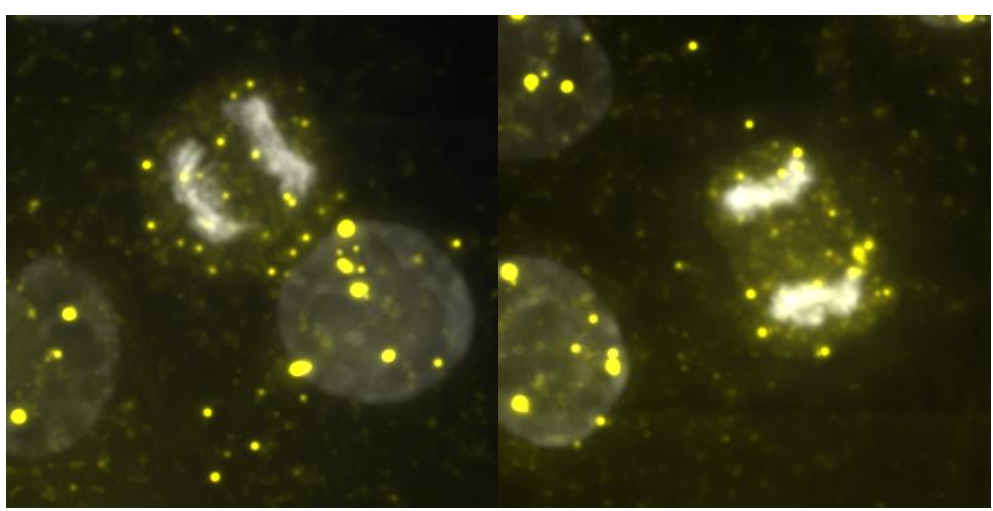

Supplementary Figure S5: Mitotic HaCaT cells with low-intensity spots. The localization of SNHG26 (yellow) in mitotic fixed HaCaT cells stained with DAPI (grey) with spots between 100-1500 intensities. 

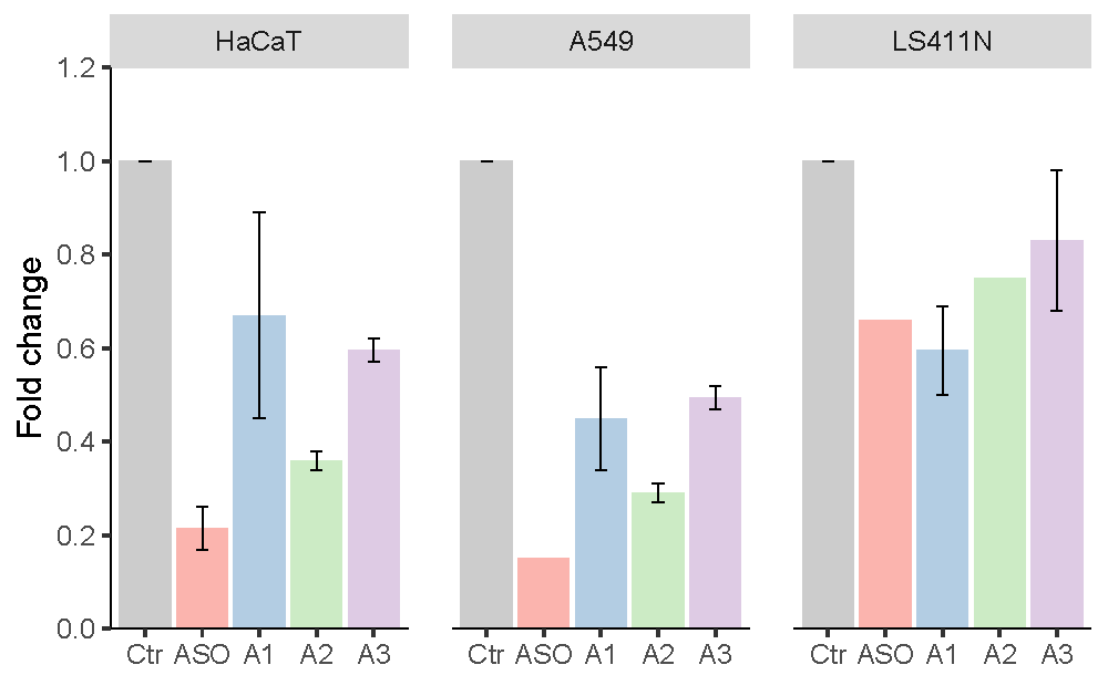

Supplementary Figure S6: Percentage downregulation of SNHG26 by using ASO and three siRNAs with different target sequences. Data are presented as fold change expressions of SNHG26 following ASO or siRNA treatment relative to control-treated cells as measured by RT-qPCR in HaCaT, A549, and LS411N cells. Bars and error bars represent mean and standard error of mean (SEM) for $\operatorname{HaCaT}(n=2)$, A549 ( $n=1$ for ASO and $n=2$ for siRNAs A1-A3), LS411N ( $n=1$ for ASO and A1, $n=2$ for A2 and $\mathrm{A} 3)$.

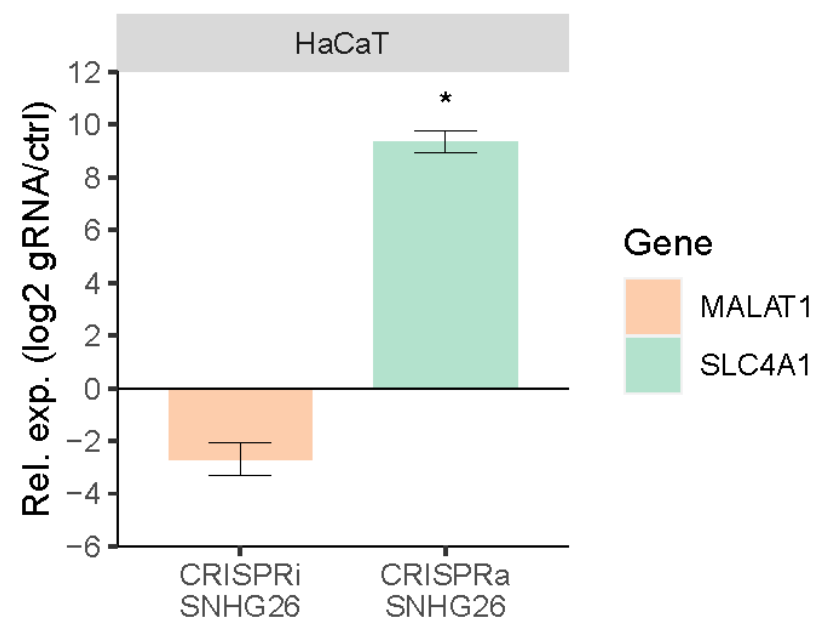

Supplementary Figure S7: The relative expression level of MALAT1 and SLC4A1 as measured by RTqPCR in response to CRISPRi/a of SNHG26 in HaCaT cells. Data are presented as fold change expressions of cells transduced with target-specific gRNA relative to control gRNA. Bars and error bars are mean and SEM of two independent replicates. Significant differences were determined by Student's $t$-test (unpaired, two-tailed), assuming equal variances $\left({ }^{*} p \leq 0.05\right)$. 


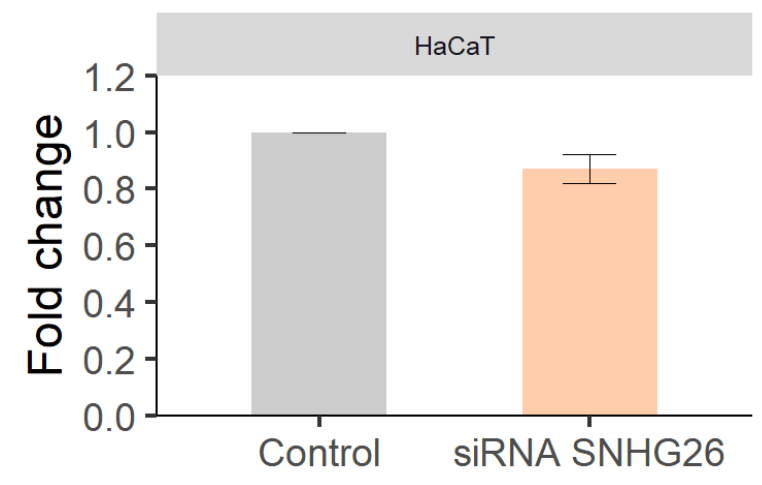

Supplementary Figure S8: Effects of siRNA-mediated knockdown of SNHG26 on metabolic activity in HaCaT cells, as measured by XTT. Data are presented as normalized absorbance $\left(A_{465 \mathrm{~nm}}-A_{630 \mathrm{~nm}}\right)$ for cells transfected with SNHG26-specific siRNA and control siRNA. Bars and error bars are mean and SEM of three independent replicates. $P$-value was calculated by Student's t-test, (unpaired, twotailed) assuming equal variances $(p=0.13)$.

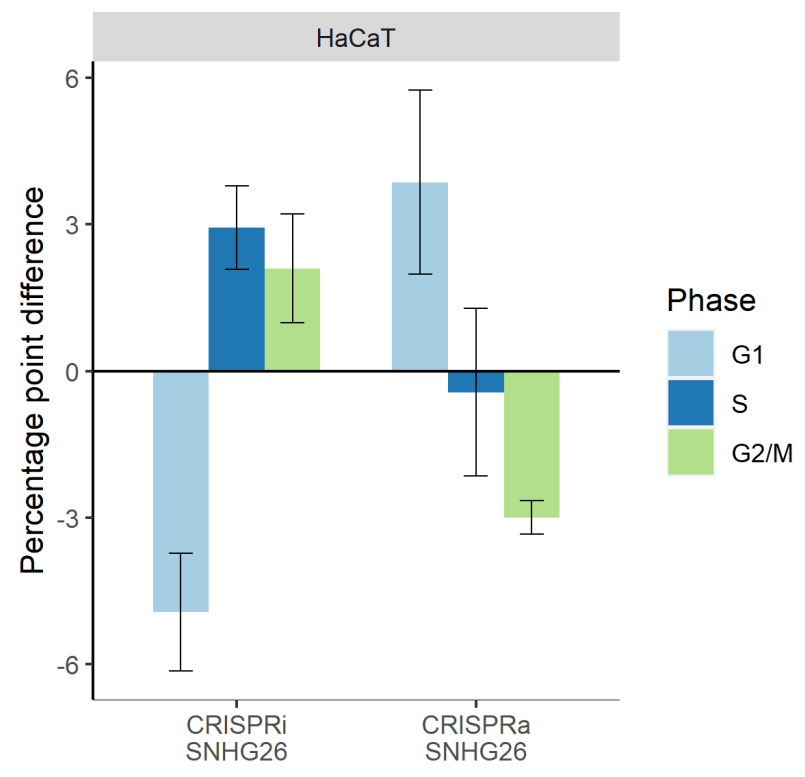

Supplementary Figure S9: The distribution of cells in G1, S, and G2/M cell cycle phases in response to CRISPRi/a modulation of SNHG26 in HaCaT cells harvested and re-seeded followed by cell cycle assay eight days after gRNA transduction. Data are the difference in percentages of $\mathrm{G} 1, \mathrm{~S}$, and G2/M cells between cells transduced with target-specific gRNA to those transduced with a control gRNA. Bars and error bars are mean and SEM of three independent replicates. ANOVA $p$-values were calculated from a hierarchical, linear model (G1: 2.32e-4, S: 0.082, and G2/M: 0.0131). 


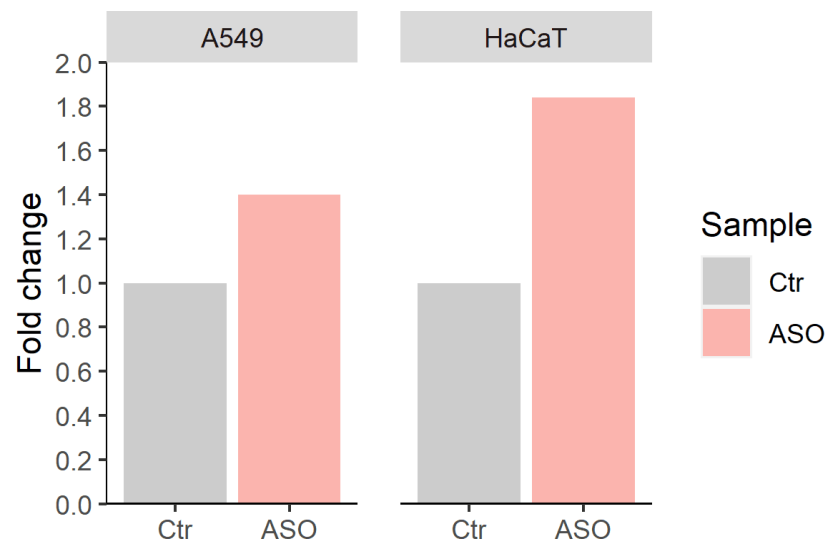

Supplementary Figure S10: We used Mitosox and FACS to determine whether ASO-mediated modulation of SNHG26 affected mitochondrial stress in HaCaT and A549 cells $(n=1)$. Data are presented as fold change fluorescence intensity of cells transduced with target-specific gRNA relative to control gRNA.

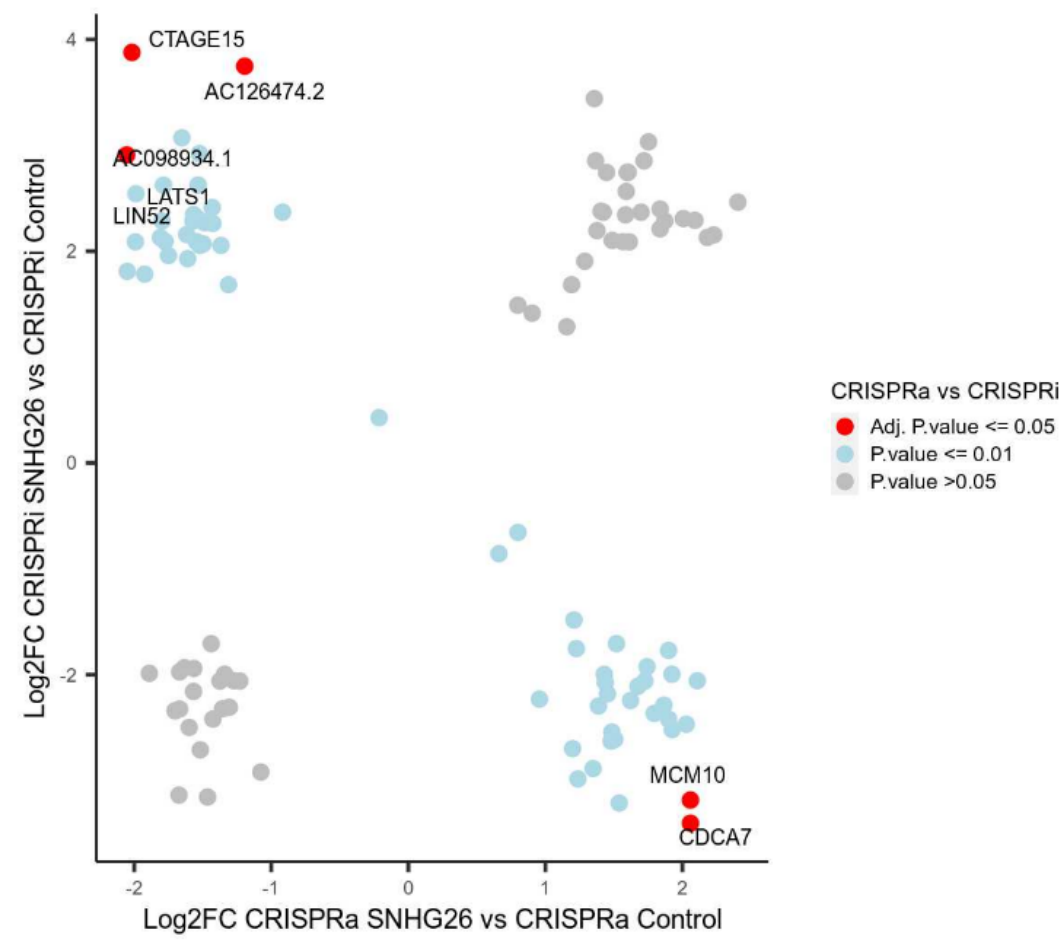

Supplementary Figure S11: A total of 110 differentially expressed genes with $P$-value $<0.05$ in both CRISPRi vs. Control and CRISPRa vs. Control. Legend shows their adjusted $P$-value in the CRISPRa vs. CRISPRi comparison. The five significant genes marked in red were differentially expressed in the opposite direction in CRISPRa compared to CRISPRi (adjusted $P$-value $<0.05$ ). 


\section{Supplementary Tables}

Supplementary Table S1: Custom Stellaris FISH probes. The probes were ordered from Biosearch Technologies and were conjugated to a Quasar670 dye in the 3'end.

\begin{tabular}{|c|c|}
\hline Sequence & Number/ID \\
\hline aagtttaaaaggggcctggg & AC005682_QUASAR670_1 \\
\hline cgaaaagggagggcactgcg & AC005682_QUASAR670_2 \\
\hline atcttgaaactccaccaagc & AC005682_QUASAR670_3 \\
\hline tcactgattctttcaagcgc & AC005682_QUASAR670_4 \\
\hline accactcctctacttgaaaa & AC005682_QUASAR670_5 \\
\hline tgtagatagtgaccccaaac & AC005682_QUASAR670_6 \\
\hline tgacttatgtcccaagagtg & AC005682_QUASAR670_7 \\
\hline attgtgtgcatgagtcactt & AC005682_QUASAR670_8 \\
\hline caatacacaactgccgtctg & AC005682_QUASAR670_9 \\
\hline tttttgcagcactgatgagc & AC005682_QUASAR670_10 \\
\hline tgttgttgccatccagaagg & AC005682_QUASAR670_11 \\
\hline aatgctgctgtggatacagc & AC005682_QUASAR670_12 \\
\hline atacatcagaggtgagattt & AC005682_QUASAR670_13 \\
\hline catctcatgcccacaacaat & AC005682_QUASAR670_14 \\
\hline caacattttccatatcccac & AC005682_QUASAR670_15 \\
\hline cagtagtattcggaatggcg & AC005682_QUASAR670_16 \\
\hline ggaaagtaatgctgcaggga & AC005682_QUASAR670_17 \\
\hline gtatttaccaaggacatcct & AC005682_QUASAR670_18 \\
\hline acccaagaccaattactcag & AC005682_QUASAR670_19 \\
\hline cgtagtttatgcagcatcac & AC005682_QUASAR670_20 \\
\hline ttttagccagcttttcagag & AC005682_QUASAR670_21 \\
\hline ggacaaggaatgcagactgg & AC005682_QUASAR670_22 \\
\hline ccttcattactccaaggaaa & AC005682_QUASAR670_23 \\
\hline ctatccctcttctaagaagc & AC005682_QUASAR670_24 \\
\hline tgactcacaacccatacttg & AC005682_QUASAR670_25 \\
\hline cctgtggttagacctattac & AC005682_QUASAR670_26 \\
\hline gaaaatgctcttggtcacca & AC005682_QUASAR670_27 \\
\hline ctgctcatacgggcaagatg & AC005682_QUASAR670_28 \\
\hline tcctaagggacatctgaaga & AC005682_QUASAR670_29 \\
\hline agtggcagggaaggtatgaa & AC005682_QUASAR670_30 \\
\hline taaggggatttggtagtggg & AC005682_QUASAR670_31 \\
\hline tctgcattgctaggctatag & AC005682_QUASAR670_32 \\
\hline cagaggttctatattggaca & AC005682_QUASAR670_33 \\
\hline attttcctgggtgatgctat & AC005682_QUASAR670_34 \\
\hline tactgactgcaaccactcat & AC005682_QUASAR670_35 \\
\hline agttgattctgcagaactgt & AC005682_QUASAR670_36 \\
\hline
\end{tabular}


Supplementary Table S2: Oligos used for guide RNA (gRNA) cloning.

\begin{tabular}{lll}
\hline Gene primer & gRNA sequence (in bold) & CRISPRi/a \\
\hline SNHG26_1_F & CACCGGGGCGGGTGCTGGACCCGG & CRISPRa \\
SNHG26_1_R & AAACCCGGGTCCAGCACCCGCCCC & \\
SNHG26_2_F & CACCGGACGCAGGAGCCGACCACG & CRISPRi \\
SNHG26_2_R & AAACCGTGGTCGGCTCCTGCGTCC & \\
neg_C_Sg2_F & CACCGTGCGATGGGGGGGTGGGTAGC & Non-target negative control \\
neg_C_Sg2_R & AAACGCTACCCACCCCCCCATCGCAC & \\
MALAT1_Ci_F & CACCGCAGCCCGAGACTTCTGTAA & CRISPRi positive control \\
MALAT1_Ci_R & AAACTTACAGAAGTCTCGGGCTGC & \\
SLC4A1_Ca_F & CACCGTCAGGAGAACCATGGGGACC & CRISPRa positive control \\
SLC4A1_Ca_R & AAACGGTCCCCATGGTTCTCCTGAC & \\
TOMM7_1_F & CACCGTGGTTGCGATCATGGCTGG & CRISPRa \\
TOMM7_1_R & AAACCCAGCCATGATCGCAACCAC & \\
TOMM7_2_F & CACCGTCGTGAGCGTCGCCAGCAG & CRISPRi \\
TOMM7_2_R & AAACCTGCTGGCGACGCTCACGAC & \\
\hline
\end{tabular}

$\mathrm{F}=$ forward, $\mathrm{R}=$ reverse, $\mathrm{Ci}=\mathrm{CRISPRi}, \mathrm{Ca}=\mathrm{CRISPRa}$

Supplementary Table S3: Antisense oligo and siRNAs used in RNA interference experiments.

\begin{tabular}{lllll}
\hline Target IncRNA & Alias & Cat. No. & Producer & Sense sequence \\
\hline SiRNA neg control & Ctr & SIC001 & Sigma & \\
SNHG26 & A1 & CTM-431276 & Dharmacon & GGACAUAAGUCACGGAAGUUU \\
SNHG26 & A2 & CTM-431277 & Dharmacon & GAAAGGAGGCUGAGUAAUUUU \\
SNHG26 & A3 & CTM-431278 & Dharmacon & GCAUAAACUACGUGGUUGAUU \\
SNHG26 & A4 & Custom & Sigma & CUGCAUUCCUUGUCCUCAU \\
SNHG26 & ASO & 339517 LG00221049 & Qiagen & GGAAGCCACAGTAGTA \\
Antisense LNA GapmeR & Ctr & 339515 LG00000002 & Qiagen & AACACGTCTATACGC \\
Neg ctr A & & & & \\
\hline
\end{tabular}

Supplementary Table S4: Primers used for RT-qPCR.

Qiagen QuantiTect Primer Assays (249900) were used for mRNA expression analysis and Qiagen $\mathrm{RT}^{2}$ IncRNA. PCR assays (330701) were used for IncRNA expression analysis

\begin{tabular}{lll}
\hline Gene & Primer assay & Cat.no \\
\hline GAPDH & Hs_GAPDH_1_SG QuantiTect Primer Assay & QT00079247 \\
TOMM7 & Hs_TOMM7_1_SG QuantiTect Primer Assay & QT00018718 \\
FAM126A & Hs_FAM126A_1_SG QuantiTect Primer Assay & QT00014854 \\
SLC4A1 & Hs_SLC4A1_1_SG QuantiTect Primer Assay & QT00068502 \\
SNHG26 & RT $^{2}$ IncRNA qPCR Assay for Human LOC101927841 & LPH07369A \\
MALAT1 & RT $^{2}$ IncRNA qPCR Assay for Human MALAT1 & LPH18065A \\
\hline
\end{tabular}


Supplementary Table S5: Custom primers targeting transcriptional start site (TSS) used for RTqPCR. Custom DNA oligos were purchased from Sigma-Aldrich.

\begin{tabular}{ll}
\hline Oligo name & Sequence $\mathbf{5}$ ' to $\mathbf{3}^{\prime}$ \\
\hline TOMM7_forward & GGGGGCAAAAGAAAGAGTCAC \\
TOMM7_reverse & TGGGAGAAGAACCGGGAAAG \\
FAM126a_forward & TCCCGAGTAGCAGCACCACC \\
FAM126a_reverse & AGTCAGTGAGAGGAGGGGGAAG \\
\hline
\end{tabular}

Supplementary Table S6: Human control qPCR primer sets from Active Motif.

Human Control qPCR Primer Sets are designed to serve as positive or negative ChIP controls when performing chromatin immunoprecipitation (ChIP) with human samples. Each primer set is a mixture of forward and reverse primers that have been validated for QPCR and endpoint PCR of ChIP samples from multiple human cell lines.

\begin{tabular}{llll}
\hline Primer set & Location & Cat. No. & Control for \\
\hline Human positive control primer set GAPDH-2 & GAPDH intron 1 & 71006 & H3K4me3 and Pol II \\
Human positive control primer set MYT1 & MYT1 promoter & 71007 & H3K27me3 \\
Human negative control primer set 1 & Gene desert chr. 12 & 71001 & H3K4me3, Pol II, H3K27me3 \\
\hline
\end{tabular}

\section{Supplementary Dataset}

Supplementary Dataset S1: A list of 1623 genes that were differentially expressed ( $p$-value $<0.05)$ in CRISPRa vs. CRISPRi. The results of Limma toptable function from individual (CRISPRa vs. Control and CRISPRi vs. Control) and joint analysis (CRISPRa vs. CRISPRi).

\section{References}

1. Nguyen, N.T.T., et al., Genomicus 2018: karyotype evolutionary trees and on-the-fly synteny computing. Nucleic Acids Res, 2018. 46(D1): p. D816-D822. 